\title{
THE DEMAND FOR POST-PATENT PRESCRIPTION PHARMACEUTICALS
}

Judith K. Hellerstein

Working Paper No. 4981

\section{NATIONAL BUREAU OF ECONOMIC RESEARCH 1050 Massachusetts Avenue \\ Cambridge, MA 02138 \\ December 1994}

This is a substantially revised version of parts of my Ph.D dissertation at Harvard University. I am grateful for the comments provided by Eli Berman, Ernie Berndt, Gary Chamberlain, Iain Cockburn, David Cutler, Sara Ellison, Ed Glaeser, Shane Greenstein, Zvi Griliches, Hank Farber, Guido Imbens, Larry Katz, Bruce Meyer, Ariel Pakes, Gary Solon, Phillip Swagel, and participants of seminars at the NBER and numerous universities. In addition, I thank Sandra Decker and the National Center for Health Statistics for providing data. Financial support was generously provided by the Sloan Foundation. This paper is part of NBER's research programs in Health Care and Productivity. Any opinions expressed are those of the author and not those of the National Bureau of Economic Research.

(C) 1994 by Judith K. Hellerstein. All rights reserved. Short sections of text, not to exceed two paragraphs, may be quoted without explicit permission provided that full credit, including () notice, is given to the source. 


\title{
THE DEMAND FOR POST-PATENT PRESCRIPTION PHARMACEUTICALS
}

\begin{abstract}
This paper examines why physicians continue to prescribe trade-name drugs when less expensive generic substitutes are available. I utilize a data set on physicians, their patients, and the multi-source drugs prescribed to study the prescription habits of physicians in prescribing generic and trade-name drugs. The results indicate that almost all physicians prescribe both types of drugs to their patients. There is, however, persistence in the prescription behavior of physicians, so that some physicians are more likely to prescribe trade-name drugs, while others more often prescribe generics. While much of this persistence cannot be explained by observable characteristics of the physician or the physician's patients, patients who are treated by physicians with large numbers of HMO or pre-paid patients are more likely to be prescribed generics, and there is wide regional variation in the propensity of physicians to prescribe generic drugs. The results are most consistent with an explanation of physicians' prescription behavior based on habit persistence.
\end{abstract}

Judith K. Hellerstein Department of Economics Northwestern University 2003 Sheridan Road Evanston, IL 60208 and NBER 


\section{Introduction}

In 1989 , over $70 \%$ of pharmaceutical prescriptions were written for multi-source drugs, that is, drugs for which both generic and trade-name versions are available. Yet of these multisource prescriptions, less than $30 \%$ specified the generic version of the drug. Since generics are generally priced 30-60\% lower than their trade-name counterparts (Grabowski and Vernon, 1990), substantial cost savings could be realized in this $\$ 40$ billion per-year market if physicians were more willing to prescribe generics to their patients.

In this paper, I examine why physicians prescribe trade-name drugs, even when less expensive generic equivalents exist. I focus on the effects of habit persistence and agency on the prescription decision of whether to prescribe a trade-name drug or its generic equivalent. Using data from a survey of physicians, their patients, and the drugs prescribed, I examine whether physicians make prescription decisions on a case by case basis or whether they systematically prescribe the same versions (trade-name or generic) to all patients. I test whether physicians are more likely to prescribe generics to patients who do not have insurance coverage for prescription pharmaceuticals. I also examine the effects of state legislation on generic prescription.

The fact that generics have not captured a greater share of prescription pharmaceuticals is puzzling. In order for a generic drug to be marketed, the Food and Drug Administration (FDA) requires that the generic manufacturer prove that its drug is virtually identical to its trade-name counterpart. This minimizes potential quality differentials between the trade-name and generic of the sort that may exist in other markets with generic goods. Furthermore, the decision-making agent for prescribing drugs is the physician, not the end-user of the drug, the patient. It seems reasonable to assume that physicians are fully cognizant of the FDA procedures for generic approval, and therefore likely to trust the efficacy of generics. 
Given this framework, possible explanations for the paucity of generic prescriptions include the existence of information imperfections, agency problems, and moral hazard in the market for prescription pharmaceuticals.

Although physicians are presumably paid to collect and disseminate information about pharmaceuticals, full information may not exist. After the patent on a trade-name drug expires, it may take time for information about the existence and name of the generic to diffuse. In addition, a risk-averse physician may not prescribe a generic until its efficacy is well established. Finally, physicians may not know the exact cost savings involved in prescribing the generic version of a drug since drug prices are not well advertised. This is complicated by the existence of differing (and often confusing) state legislation concerning generic substitution by pharmacists for prescriptions specifying trade-name drugs.

The issues of agency and moral hazard in this market are two-fold. First, since physicians do not bear the costs of the drugs they prescribe, they may not invest in the knowledge required to prescribe cost-effective drugs. Physicians may therefore persist in prescribing expensive trade-name drugs simply as a matter of habit, even though cheaper alternatives exist. Second, even if physicians do internalize the costs to their patients of pharmaceuticals, they may not internalize the costs to their patients' insurance carriers. This would induce the typical moral hazard associated with insurance, whereby the physician would be more likely to prescribe a trade-name drug to a patient if a third party payer bears the cost of the prescription.

The results indicate that the majority of physicians prescribe both generic and tradename drugs to their patients. Physicians therefore cannot be classified simply as "high cost" or "low cost" when it comes to prescribing drugs. There is evidence, however, of persistence in the prescription behavior of physicians, even after controlling for observable characteristics of the physicians and their patients, so that some physicians more often prescribe trade-name drugs, while other physicians tend to prescribe generics.

The results do indicate that older patients and women are less likely to receive generics 
than the rest of the population, but the magnitudes of these differences are small. In addition, there is no evidence of prescription practices which are consistent with moral hazard in insurance; patients with insurance are no more likely than patients without insurance to receive trade-name drugs.

Physicians also do not appear to respond to the direct pecuniary incentives of state legislation about generic substitution when prescribing drugs. Twelve states have passed legislation requiring pharmacists to dispense generic drugs regardless of which version of a drug is written on the prescription. The intended purpose of this legislation is to ensure that generics will be dispensed without relying on physicians to explicitly write generic prescriptions. In theory, then, physicians in these states should always be free to prescribe trade-name drugs to their patients, and as a result should have no pecuniary incentive to even learn about generics. The results indicate, however, that physicians in these twelve states are no more likely to prescribe trade-name drugs than their colleagues in states which do not require the pharmacist to dispense generic drugs.

There is significant regional variation in the propensity of physicians to prescribe generics. Patients in the South are over $8 \%$ less likely than those in the Northeast to receive generic drugs. In addition, patients who belong to HMOs or other pre-paid plans are more likely to receive generic drugs, but this result is not due to these patients' insurance status per se. Rather, physicians who are affiliated with HMOs or other pre-paid plans are more likely to prescribe generic drugs to any patient regardless of that patient's insurance carrier. This result could be due to the emphasis on cost containment in HMOs which makes physicians more sensitive to the existence of generics. Alternatively, there may be self-selection of low cost physicians into practices which treat patients covered by managed care plans.

Finally, while physicians do vary their prescription practices across all drugs, physicians are prone to prescribing either trade-names or generics. In particular, physicians tend to repeatedly prescribe the same version of a given drug. That is, for a given drug, some physicians persist in prescribing the generic version, while others persist in prescribing the 
trade-name drug. There are two possible explanations for this result. The first is that for each drug, some physicians find the generic version to be of equal or superior quality to the trade-name, while other physicians prefer the trade-name version, with the distribution of these preferences differing across drugs. The second possibility is that physicians do not evaluate quality and price when prescribing drugs, but rather persist in prescribing a certain version of each drug simply out of "habit." Given that none of the important observable determinants of the prescription behavior are patient-specific, and given that physicians do not appear to respond to the pecuniary incentives of state legislation or moral hazard, habit seems the most likely explanation for the persistence of prescription behavior.

The paper proceeds as follows. Section 2 reviews the basic facts and existing literature involving generic pharmaceuticals, insurance coverage, and moral hazard. Section 3 describes the characteristics of the data set used and reports relevant summary statistics. Section 4 introduces a model of physician demand for generics and Section 5 discusses an empirical estimation framework based on this model and the data. Section 6 discusses the estimation results and their interpretation. Section 7 contains the conclusion and suggestions for future research.

\section{Background and Related Literature}

\subsection{The Introduction of Generics}

Prior to 1984 , generic pharmaceuticals were relatively uncommon. Any firm that wanted to market a post-patent expiration generic had to prove to the Food and Drug Administration (FDA) the drug's efficacy and safety by conducting exactly the same tests as those required of the original innovator. This constituted a substantial barrier to entry. In 1984, Congress passed the Drug Price Competition and Patent Term Restoration Act of 1984, commonly known as the Waxman-Hatch Act. This legislation eliminated the strict requirements for FDA approval of generic substitutes and replaced it with one which requires much less 
stringent testing.

The Waxman-Hatch Act stipulates that a firm wishing to gain approval for distribution of a generic drug must prove to the FDA that its drug contains the same active ingredients as the original patented drug; that it is of the same dosage form; is identical in strength and method of administration (oral, injection, etc.); and meets FDA standards for quality. In addition, tests must establish that the generic is bioequivalent to the original drug in the sense that it must have the same rate and extent of absorption of the active ingredient as the original drug. The generic may differ from the trade-name drug in its inert ingredients such as coloring, preservatives, and binding agents. The generic may also differ in shape, packaging, labelling and shelf life. These differences may be important as they may cause unintended side effects in some patients such as stomach discomfort due to the binding agents or allergic reactions due to added coloring. In addition, for some patients, consistency in the shapes and colors of drugs may be important to ensuring that the patient takes the correct dosage.

Passage of the Waxman-Hatch act was followed by a dramatic increase in the number of generic drugs in the market (Grabowski and Vernon, 1990). In mid-1988, however, a House of Representatives subcommittee began investigating charges that certain FDA officials were accepting bribes to quicken the pace of approval of certain generics. These charges were proven true in May, 1989. In addition, in July 1989, the FDA began investigating various generic manufacturers for falsifying the tests submitted to the FDA to win approval for the sale of their drugs. Although the FDA found irregularities at many of the plants under investigation, there was no evidence that the safety or efficacy of the drugs were ever compromised. There was nonetheless speculation that physicians were beginning to question the use of generics (New York Times, 1989). In fact, between 1989 and the middle of 1990, there was a decline in generic sales for the only time since passage of the Waxman-Hatch Act (Boston Consulting Group, 1993). 


\section{$2.2 \quad$ State Substitution Laws}

The other major legislative change which has affected generic entry has been the repeal of state anti-substitution laws. Twenty-five years ago, most states had some kind of law which prohibited a pharmacist from dispensing any drug other than the one expressly written by the physician. This barred generic substitution by pharmacists. By 1989 , none of these laws remained.

Most states have what are known as "permissive substitution laws" which allow a pharmacist to substitute a therapeutically equivalent drug for that written on the prescription. ${ }^{1}$ Twelve states have mandatory substitution laws which require the pharmacist to substitute if the generic drug is in stock and is cheaper than the prescribed drug. ${ }^{2}$ In both cases, the physician can override the possibility of substitution by prohibiting substitution on the prescription itself. Mandatory substitution laws have the potential to affect two aspects of physician behavior. These laws remove any pecuniary incentives for a physician to write a generic prescription since, in theory, the physician can write a trade-name prescription and assume that the pharmacist will substitute a generic. In addition, since physicians have no incentive to write generic names on prescriptions, they have no incentive to invest the time needed to learn the generic names for drugs.

There are two methods of substitution prevention. Some states utilize the "two-line method" where the physician signs the prescription either on a line which reads "brand medically necessary" or on a line which reads "substitution allowed." 3 Other states have a one-line method (also called "active substitution method") where the physician signs the prescription in only one place and in order to actively prohibit substitution must either

\footnotetext{
${ }^{1}$ For a detailed study of the effects of state legislation on pharmacist substitution in the early 1980 's, see Masson and Steiner, 1985.

${ }^{2}$ The states with mandatory substitution laws are: Florida, Hawaii, Kentucky, Massachusetts, Mississippi, New Jersey, New York, Pennsylvania, Rhode Island, Vermont, Washington, West Virginia.

${ }^{3}$ States with the two-line method are: Alabama, Arizona, Idaho, Illinois, Indiana, Kansas, Mississippi, Missouri, North Carolina, Rhode Island, South Carolina, South Dakota, Tennessee, Texas, Vermont, Washington, Wyoming.
} 
check a pre-printed box on the prescription form or write "brand medically necessary." Interestingly, this seemingly minor difference has a huge impact on whether substitution is allowed. In 1989, substitution was prohibited in $41 \%$ of two-line brand-written prescriptions but in only $11 \%$ of brand written prescriptions which require more than a signature from the physician. (Drug Topics, 1990). This clearly suggests that even very small transactions costs affect physician decisions.

With all of this legislation to promote substitution, it is rather surprising that generic substitution is not more prevalent that it appears to be. Generic substitution occurred in less than $30 \%$ of trade-name-written prescriptions in 1989, while Caves et al. (1991) report that nearly all prescriptions written for generics were, in fact, filled with the generic drug. This is even more surprising when one considers that Florida, New York, and Massachusetts, three states with high demand for prescription drugs, are three of the states with both mandatory substitution laws and one-line prescription pads. Since physicians in one-line states seldom prohibit substitution and since it is mandatory by law for the pharmacist to substitute when not prohibited from doing so, substitution should occur in these states most of the time. It seems that strict adherence to state legislation on the part of pharmacists is probably not occurring, although recent data on this are sketchy. Because generic substitution does not occur in the majority of the cases- either because of physician prohibition or pharmacist or patient preferences - the actual drug name written on the prescription by the physician still has the greatest impact on which type of drug the patient will receive.

\subsection{Physician Practices: Moral Hazard and Information}

Between 1984 and 1989, the Producer Price Index for prescription pharmaceuticals rose at an average annual rate of approximately $9 \%$. While there is some question as to the accuracy of this figure (see Berndt et al., 1990), the perceived high and rising costs of prescription pharmaceuticals have been the subject of a great deal of attention recently in government, the popular press, and academic research, and as part of the greater debate on health care 
costs. ${ }^{4}$

Although there are those who think that these phenomena are the natural result of perfectly competitive factors such as increasing $R \& D$ costs, many researchers have speculated that the high costs of pharmaceuticals, as with the rest of health care costs, are the result of market imperfections.

One of the most commonly discussed imperfections in the general market for health care is "supplier-induced demand." In this scenario, the physician, acting as agent for the patient, shifts out the patient's demand curve, causing the patient to demand more services at every price. Since physicians generally do not benefit financially from the prescription choices they make for their patients, ${ }^{5}$ supplier-induced demand is not an issue in the market for prescription drugs. It might seem, then, that physicians should act as perfect agents in prescribing drugs (as suggested by Dranove, 1989). Collecting information, however, is not costless to the physician, so that the physician may choose not to spend the resources necessary to keep abreast of changes in available pharmaceuticals. Generic versions of a drug do not appear until after the patent on the original trade-name drug expires. It may take time for physicians to learn of the existence of a generic or its exact name, especially as the names of generic drugs are often long and complicated. It may also take time for the physician to gain confidence in the efficacy of a generic. In addition, although the price differential between generic and trade-name drugs should be one of the main factors driving generic demand, some evidence suggests that physicians have little knowledge of actual drug prices (Temin, 1980). Despite large expenditures on advertising in the industry, ${ }^{6}$ promotional

\footnotetext{
${ }^{4}$ For a good review of the academic literature on overall health care costs, see Newhouse (1992) and the references therein.

${ }^{5}$ Only $2 \%$ of physicians dispense their own drugs (Shah, 1992), and the practice is outlawed in some states. This is not to say that physicians do not benefit from relationships with pharmaceutical companies. The direct advertising that pharmaceutical companies undertake, called "detailing", can lead to lucrative rewards for physicians. It is unlikely, however, that physicians perceive that these rewards result from the actual prescriptions a physician writes.

${ }^{6}$ Caves et al. (1991) find that for their sample of drugs, average sales promotion as a proportion of sales was $6 \%$ in the year in which the patent expired.
} 
information seldom reports actual prices. An interesting piece of evidence pointing to the lack of information on the part of physicians is the success of Medco, a large mail-order pharmacy, which contacts physicians to try to convince them to substitute lower priced drugs for the drugs they have prescribed. Medco convinces physicians to switch to the lower-cost product in one-quarter to one-half of the cases it pursues (Boston Consulting Group, 1993). This indicates a willingness of some physicians to be price-sensitive given adequate information on efficacy and price.

Although it is difficult (if not impossible) to measure information diffusion, there is evidence in health care which is consistent with imperfect information. For instance, there is ample documentation of regional differences in levels of care for various health-related procedures which are not associated with observable characteristics of the regions. Phelps (1992) argues that, "this evidence on 'variations' (and the failure of normal explanations of the variations) leaves almost by default the idea that incomplete diffusion of information must be largely responsible."

Even in the presence of costless diffusion of information about generics, there may still be agency problems associated with prescription decisions. The physician may be acting as perfect agent for the patient, but not for the patient's insurer. In the prescription counterpart to the moral hazards associated with insurance (see Feldstein, 1976), the physician may not internalize the portion of the cost of a prescription paid by insurance, which may lead the physician to make a socially sub-optimal prescription decision.

The results on prescription drug usage from the Rand Health Insurance Experiment (HIE), which are summarized in Newhouse (1993), from a nice complement to the results in this paper, and support the assumption that the physician is the relevant agent in the prescription decision. The HIE results indicate that, in a controlled experiment of the effects of insurance on health care, expenditures on prescription drugs are related to the number of visits to the physician rather than on the cost of prescription conditional on a visit. In addition, the average cost of a prescription does not vary across the type of insurance plan 
to which patients in the experiment were assigned, nor do generic prescription rates vary by plan. Therefore, there is no evidence in the HIE that patients with lower insurance reiumbursement rates seek out lower cost drugs.

\subsection{Insurance Coverage and Prescription Pharmaceuticals}

Although Medicaid recipients make up only $7 \%$ of the population, Medicaid accounts for $10-15 \%$ of total prescription drug sales (Boston Consulting Group, 1993) and approximately $50 \%$ of third party payments for pharmaceutical products (Frank and Salkever, 1991). This is probably due to both a greater need for drugs by Medicaid patients and the fact that Medicaid has generous prescription drug coverage relative to other insurance plans. Since Medicaid is a state administered program, rules for reimbursement of prescription drugs differ across states. In 1990, the federal government passed the Omnibus Reconciliation Act of 1990 (OBRA), which set mandatory rebate levels on Medicaid prescription drugs in all states. Prior to 1990, however, state policies on substitution differed. As an inducement for pharmacists to substitute generics, some states reimbursed pharmacists only for the cost of the generic substitute (if it existed), no matter which version of the drug was dispensed. Other states did not distinguish between generics and trade-name drugs in reiumbursement levels, but simply excluded certain expensive drugs altogether from their Medicaid formulary (the list of drugs approved for sale to Medicaid patients). Presumably, these differing laws did not affect a physician's prescription decision, since under all Medicaid programs, the patient was required to pay only a small fixed co-payment $(\$ .50$ to $\$ 2.00)$ for each prescription, no matter the cost. This coverage makes Medicaid the most generous third party payer for prescription pharmaceuticals.

Medicare does not currently pay for any portion of prescription drugs, but a large fraction of Medicare recipients are also covered by other insurance plans. In 1987, for example, $10 \%$ of Medicare recipients were also covered by Medicaid, and a full $75 \%$ were covered by private insurance. Interestingly, the mean expenditure on prescription drugs per beneficiary was 
$\$ 212$ for Medicare patients with no other insurance, $\$ 266$ for Medicare patients who also had private insurance, and $\$ 339$ for Medicare patients who also qualified for Medicaid (Dept. of Health and Human Services, 1989). This is consistent with a simple theory of physician agency where physicians internalize only the costs of drugs to their patients and do not internalize the costs to insurance companies. This would lead physicians to prescribe fewer and/or cheaper drugs to those with less outside insurance. Since Medicaid patients may be sicker on average than others, and since the choice to carry private insurance may be endogenous, these figures are only suggestive.

Health Maintenance Organizations (HMOs) have various policies regarding generic substitution and coverage of prescription drugs. A 1988 survey of HMOs (Doering et al. 1988) found that over $70 \%$ of HMOs did have some sort of policy regarding generic substitution by the HMO pharmacy. Of the 188 HMOs who responded to the survey, $38.3 \%$ substituted generics except when prohibited by the physician and $32.5 \%$ dispensed generics except when the patient insisted on receiving the trade-name drug. In cases where the recipient refused the generic, the patient was usually required either to pay the price differential between the generic and the trade-name drug or to pay a higher copayment.

There is wide heterogeneity across private insurance plans in the coverage of prescription pharmaceuticals. Data from 1989 and 1990 indicate that 25-30\% of private insurance plans had some prescription drug coverage. ${ }^{7}$ Of those individuals who were covered by some prescription drug coverage, $3 \%$ had full coverage for prescription drugs, $30 \%$ had some copayment or separate deductible for prescription drugs, $61 \%$ had prescription drug coverage under the same rules as all coverage in their plan, and $7 \%$ were covered by other types of limits on payments (U.S. Congress, 1993).

\footnotetext{
${ }^{7}$ The data on private insurance include the $14 \%$ of individuals covered by HMOs.
} 


\section{Empirical Motivation and Summary Statistics}

As described in Section 2, the forces determining the prescription choice of physicians are complex and numerous. Before outlining a formal model of the prescription choice or discussing an estimation strategy, it is useful to first consider relevant tabulations which are contained in the data set employed here, the 1989 National Ambulatory Medical Care Survey (NAMCS). Full details of the data and their construction appear in the Data Appendix. The data consist of observations of 38,384 patient-visits to 1223 office-based physicians over the course of 1989. Physicians selected in the survey recorded information on a random sample of patients that visited their offices over a two week period. The distribution of patient-visits per physician in the sample is graphed in Figure 1. The average physician recorded data for approximately 30 patients, although there is a lot of variability in the number of patients per physician. The sampling scheme was designed so that physicians with larger practices recorded data for more patients, although not in fixed proportions to the overall sizes of the practices.

For each patient-visit, the physician recorded demographic characteristics of the patient (age, sex, race, ethnicity) as well as information about the medical condition of the patient. In addition, the physician recorded the names of all medications ordered. It is important to understand that medications ordered were not necessarily the medications ultimately dispensed to the patient by the pharmacist. That is, the pharmacist could have substituted a generic version of the drug for a trade-name prescription. These data contain no information on what drug was ultimately dispensed to the patient. In addition, the data unfortunately do not indicate whether or not the physician prohibited substitution on the prescription pad. The data, however, contain the state in which the physician practices, so that it is possible to control roughly for the likelihood of substitution given the relevant state laws. Finally, the physician was asked to record the expected source(s) of payment for the visit: selfpay, medicare, medicaid, blue cross/blue shield, other commercial insurance, HMO/prepaid 
plans, no charge, or other. Table 1 contains summary statistics for the overall sample of patients. The most striking thing to note is that $27.3 \%$ of the sample is classified as being self-insured, which is a much higher figure than reported elsewhere. This discrepancy is most likely due to miscoding in the NAMCS data of insurance payments. Physicians in the survey were instructed to record a third-party payer as the source of payment if the patient paid at the time of the visit but was to be reiumbursed later, but it is likely that physicians recorded some of these patients as paying for the visit themselves. The relevant information for the prescription decision of a physician, however, is the physician's perception of whether the patient has insurance. If this is, in fact, what the physician recorded in the data, then the insurance data are accurate for the problem at hand. This issue is discussed in further detail below.

Of the patients in the survey for whom demographic and insurance data exist, 9317 of them were given prescriptions for one of 564 uniquely named multi-source prescription drugs. These drugs represent 182 different generic compounds for which both trade-name and generic versions were available in $1989 .{ }^{8}$ Prescriptions for these multi-source drugs are relatively frequent. Only $9 \%$ of the physicians in the survey had no patients to whom they prescribed one of these drugs.

Over the sample of patients, $27.6 \%$ of those receiving multi-source drugs were prescribed the generic version of the drug. This is higher than the $19 \%$ of generically written prescriptions reported by Caves, et al. (1991) over the same period. There are a few possibile explanations for this discrepancy. The first is that the Caves data are derived from a drugstore based audit, rather than a physician survey. In addition, there are approximately 1000 observations in the NAMCS for which the drug name was listed as "OTHER" and for which

\footnotetext{
${ }^{8}$ The term "generic" is used rather loosely in many discussions of prescription pharmaceuticals. It can variously refer to versions of a drug which are sold under the actual generic name, or to drugs which are not marketed by the original innovator of the drug. In this analysis, I use the former definition. Drugs classifed as generics are those for which the physician recorded the name of the generic entity in the survey (and presumably on the prescription pad as well). Tradename drugs refer to any drugs prescribed under a name other than the generic.
} 
no additional information is given. The drugs in this category were considered to be too infrequently prescribed to merit separate breakdowns in the data. It is not clear how many of these drugs are multi-source prescription drugs. These are most likely trade-name drugs, since generics entry tends to occur only in high volume drugs. This would bias upward the frequency of generic prescription in the data, but not by enough to make up for the discrepancy between these data and the Caves figures.

Another possible reason for this discrepancy is that the drug data here are self-reported by the physician, and the wording in the NAMCS concerning the recording of drug information is slightly vague. The physician was instructed to record "the same specific drug name (brand or generic)...used on any prescription." It is possible that physicians interpreted this to mean that it was acceptable to record the generic name of the drug, although that was not what was intended. There is no way to recover information on whether or not this occurred. As Figures 2 and 3 indicate, however, most physicians in the survey record prescriptions for both generic and trade-name versions, and hardly any report only prescribing generic drugs. It seems unlikely that physicians who report prescribing both versions were interpreting the questionaire incorrectly in a manner which would induce them to report the correct version of the drug for only some patients.

Table 2 contains summary statistics on the prevalence of generic prescription by the insurance status of the patient. Only patients covered by HMOs/pre-paid plans and Medicare significantly differ from patients without insurance in their likelihood of receiving a generic ( $\mathrm{t}$-statistics of -2.26 and 4.68 , respectively). Medicare patients are the least likely to receive generics, but they clearly have different medical needs than the overall population. Patients covered by HMOs or pre-paid plans are the most likely ( $32 \%$ of the time) to be prescribed generics. This is striking, since HMOs with policies mandating generic substitution by their own pharmacies eliminate any direct pecuniary incentive for the physician to prescribe the generic version of the drug, since either type of prescription will result in the generic being dispensed. Since physicians affiliated with pre-paid plans are expected to contain costs, they 
may be more sensitive to the existence of generics. In many pre-paid plans, for instance, physicians' salaries are tied to some measure of their productivity or merit (Luft, 1987), so that physicians who are perceived as "high-cost" may be penalized accordingly.

There is also a lot of heterogeneity across therapeutic drug classes in the frequency of generic prescription, as can be seen in Table 3. For the largest drug class represented in the data, Antimicrobials, $41 \%$ of the prescriptions are written for the generic, while in other drug classes generic prescription seldom occurs. Although not completely consistent across drug classes, it appears that generic penetration is more prevalent for more commonly prescribed drugs. This is not surprising considering that there are relatively large fixed costs associated with entry into a given generic market, particularly the cost of obtaining FDA approval.

This data set is unusual in that it links together patient-observations of a given physician. It is therefore possible to examine the variation across physicians in their propensity to prescribe generics. As mentioned above, Figures 2 and 3 graph the distribution of generic prescription rates for the physicians in the survey. The top graph reports the distribution for all the physicians, and the bottom for those physicians for whom multi-source drug data is observed on more than five patients. The majority of physicians in the sample do prescribe both trade-name and generic drugs. Of the $32 \%$ of physicians who never prescribe the generic version of a multi-source drug, most of them report few overall prescriptions. For instance, $24 \%$ of these physicians prescribe only one multi-source drug in the sample, and $65 \%$ prescribe multi-source drugs to five or fewer patients. These figures make it clear that physicians cannot be classified simply as "high-cost" or "low-cost" in their prescription habits, as most physicians tend to prescribe generics to some patients but not others.

Figure 4 contains a tabulation of the number of unique multi-source prescriptions made by physicians. That is, Figure 4 takes as an observation each unique drug (trade-name or generic) prescribed by a physician to at least one patient in the sample. For $67 \%$ of the observations, the physician only prescribes that unique drug to one patient. However, for the other $33 \%$ of the unique physician-drug matches, the physician prescribes the drug in 
some form to more than one patient. Figure 5 examines the 171 unique drug-physician pairs which are prescribed to more than five patients of a given physician. In over $60 \%$ (105) of the cases, the physician always prescribes the trade-name version of the drug. One might be tempted to conclude that these physicians always prefer brandname drugs, yet more than three quarters of these physicians do prescribe generics to some patients. In $26 \%$ (44) of these unique drug-physician matches, the physician always prescribes the generic version of the drug, yet almost all of these physicians prescribe other trade-name drugs to other patients. There are a variety of possible explanations for this phenomenon. The first is that physicians explicitly evaluate quality differentials for each patient and each drug, but the distribution of types of patients and types of drugs prescribed differs across physicians. The second possibility is that physicians make decisions about the efficacy of generics for each of the drugs they prescribe and then use that "rule of thumb" decision for all patients. This explanation would require the existence of heterogeneous preferences across physicians and across drugs. Finally, it is possible that physicians do not explicitly evaluate quality differentials at all when prescribing drugs but rather persist in prescribing a certain version of each drug simply out of habit. ${ }^{9}$

The first of these explanations is consistent with what is observed for the remaining $13 \%$ of these cases, where the physician prescribes the trade-name version to some patients and the generic version to others. The medical and economic explanation consistent with these last cases is that the trade-name drug differs from the generic version in ways which are relevant to some patients, perhaps in the exact dosage or packaging. A fully-informed and

\footnotetext{
${ }^{9}$ This use of the terms "habit" and "habit persistence" is not to be confused with the more technical use of the term by Heckman (1981a). Heckman distinguishes between what he calls "habit persistence," "state dependence," and "heterogeneity." Roughly speaking, these correspond respectively to the propensity of generic prescription as a function of actual generic prescription to other patients; the propensity of generic prescription as a function of generic propensity in prescriptions to other patients; and unobserved heterogeneity in generic prescription rates across physicians. Given the nature of the NAMCS data, it is impossible to separately identify habit persistence from state dependence, but the fact that, as discussed below, observed characteristics of the patient and the physician affect the prescription decision rejects a model based solely on unobserved hetergeneity.
} 
price-sensitive physician would weigh these differences against the price differential between the two versions in determining which to prescribe.

Since the state in which the physician practices is included in the data, it also is possible to consider the effects of different state rules on generic prescription rates. There is virtually no difference in the unconditional generic prescription rates between states with mandatory substitution and those without it. In states with one-line prescription pads, however, prescriptions specify the generic version of drugs significantly less often than in states with two-line prescription pads ( $25 \%$ versus $29 \%$, with the $\mathrm{t}$-statistic of the equality of the two equal to 3.81). Since physicians in two-line states forbid substitution much more frequently, this further increases the substitution differential between states with one-line and two-line pads so that patients in two-line states are much less likely to have the generic dispensed to them by a physician.

Finally, the NAMCS survey was conducted over a period starting in March, 1989 and ending in March, 1990. Each physician chosen in the sample was randomly assigned to reporting information for a two week period during the sample period. News that the FDA was investigating irregularities at generic manufacturing plants broke in the middle of July, 1989. This did not appear to have a significant effect on prescription-writing behavior. Of those prescriptions made before July, $28.24 \%$ of them were for the generic. After July, $27.53 \%$ of the prescriptions were for the generic (the t-statistic for equality of the two is -0.70 ). Of course, it is still possible that following these reports, physicians began to prohibit substitution more frequently. Data on this are unavailable, so I must assume below that an increased prohibition of substitution is not systematically related to observable characteristics of patients or physicians.

While all of this evidence may suggest explanations for the continued prescription of trade-name drugs by physicians, a formal treatment of all of these issues is necessary in order to assess their impacts on the prescription decision. The rest of the paper is devoted to this task. 


\section{The Model}

The purpose of developing a model of physician prescription behavior here is to parsimoniously fix the main issues involved with agency, risk, and information embodied in the prescription decision. The model must be applicable to a regression framework which is flexible enough to incorporate the constraints of the NAMCS data. Therefore, although prices are explicitly incorporated into the model, it should be noted that this is done for exposition only. In the ensuing empirical analysis, price data are not included; incorporating price data is left for future research and drug dummy variables are instead used as proxies for price.

First, consider a world without insurance. A price-taking patient with income $Y$ consumes two goods, $X$, the aggregate good the price of which is normalized to one, and $D$, the beneficial drug. The drug comes in either a trade-name version, with price $P_{t}$, or in a generic version with price $P_{g}$, where $P_{g} \leq P_{t}$. In states with mandatory substitution and full cost pass-through to consumers, the effective price of either version of the drug is the same so that $P_{t}$ will equal $P_{g}$. However, in order not to complicate the model unnecessarily with issues of pharmacist substitution and varying state laws, assume for now that any brand-written prescription prohibits substitution. The patient takes no more than one dose of either version of the drug.

Assume that the patient's utility function is separable in $X$ and $D$ such that $U=u(X) \cdot D$ where $u^{\prime}>0$ and $u^{\prime \prime}<0$. This assures that the patient is always prescribed some form of the drug. There may be a quality difference between the generic and the trade-name drug, so that the quality adjusted price of the generic is $P_{g}+q^{*}$, where $q^{*} \geq 0$.

In order to introduce agency issues into the problem, assume that the patient knows the utility function $u$ and income $Y$ but relies on the physician for information about $D, P_{t}, P_{g}$, and $q^{*}$. Define an indicator for generic prescription $G$, where $G=1$ if the generic version is prescribed and $G=0$ if the trade-name version is prescribed. If information is costless to the physician, then the generic will be prescribed if the quality-adjusted price of the generic 
is less than or equal to that of the trade-name drug:

$$
G=1 \text { iff } P_{g}+q^{*} \leq P_{t}
$$

Define the price differential between the trade-name drug and the generic, $P_{t}-P_{g}$, to be $\Delta P$. Then the physician prescribes the generic $(G=1)$ if:

$$
q^{*} \leq \Delta P
$$

In other words, in this case the physician acts as a perfect agent for the patient.

If it is costly for the physician to gather information, however, the physician may not act as a perfect agent for the patient. Rather than reporting to the patient that the quality differential is $q^{*}$, the physician will report an estimated quality differential $q=q^{*}+c$, where $c$ is the physician's prediction error. There are two alternative interpretations of $c$. One is that the physician is risk-averse and always overstates the quality differential. The other is that the physician has a preference for the trade-name drug which is based simply on habit. Then $c$ is the adjustment cost of breaking that habit in order to prescribe the generic.

Now assume that the patient has insurance which covers a proportion $\theta$ of the cost of the drug where $0 \leq \theta \leq 1$. If the physician acts as partial or perfect agent for the patient, but does not internalize any of the cost borne by the insurer, then the physician will prescribe the generic if:

$$
q \leq \Delta P(1-\theta) .
$$

where, as above, $q=q^{*}+c$. If insurance covers the full cost of prescriptions so that $\theta=1$, or if there is no price differential between the generic and trade-name versions, then the physician will prescribe the generic only if there is no quality differential, information is costless, and the physician does not suffer from habit persitence, i.e. $q=0$. Additionally, if the insurance plan requires the patient to pay a fixed co-payment on all prescriptions, $\theta$ is effectively equal to 1 , since the insurer pays for the entire price differential between the trade-name and generic drug. 
If the physician also internalizes a proportion $(1-\gamma)$ of the cost to the insurer of the drug, where $0 \leq \gamma \leq 1$, then Equation 3 becomes:

$$
q \leq \Delta P(1-\gamma \theta)
$$

Note that if $\gamma=0$ the physician fully internalizes both the cost of the drug to the patient and to the insurer.

Consider expanding the model to an economy of $J$ physicians and $K$ drugs. Each physician $j$ sees $I(j)$ patients. For ease of notation, let $I_{j}=I(j)$, and let $i_{j}$ denote a patient of physician $j$. Assume for simplicity that only one drug (either the trade-name or generic version) is beneficial to each patient so that $D_{k}>0$ for $k=1 \ldots K$, and $D_{d}=0$ for $d \neq k$. (either the trade-name or generic version). Then the utility function becomes

$$
U_{i,}=u_{i,}\left(X_{i j}\right) \cdot D_{k}
$$

The quality differential between the generic and trade-name version, $q_{k}$ is now drugspecific, and the parameter $c$ may have a drug-specific component (for example, if information diffusion is drug specific) and/or a physician-specific component (for example, if there is habit persistence in a physician's prescription decision or if information diffusion is physicianspecific). Assume that the drug-specific and physician-specific components are additive so that $c=c_{j}+c_{k} \cdot{ }^{10}$ Now, the $j$ th physician will prescribe the $k$ th drug in its generic form to the $i$ th patient only if:

$$
q_{k}^{*}+c_{j}+c_{k}<\Delta P_{k}
$$

or, in the case where the patient has insurance,

$$
q_{k}^{*}+c_{j}+c_{k}<\Delta P_{k}\left(1-\gamma \theta_{i j}\right)^{11}
$$

${ }^{10}$ One could also consider that $q^{*}$ and $c$ are patient-specific as well if, for instance, patients have different medical reactions to the quality differential or $c$ is affected by habit persistence on the part of patients. For notational simplicity, I do not formalize this possibility here but I do consider it in the empirical application below.

${ }^{11}$ Equation 7 assumes that the physician internalization parameter $\gamma$ is constant across physicians. Relaxing this assumption is considered in Section 5 below. 


\section{Empirical Implementation}

Assume that there is an unobserved component, $\varepsilon_{i}$, to the prescription decision outlined in Section 4. This may be due to randomness or to elements of the prescription choice which are unobservable to the researcher. Then Equation 7 can be reformulated in a probabilistic setting so that the probability that the $j$ th physician prescribes the $k$ th drug in its generic form to the $i$ th patient is:

$$
\left.\operatorname{Prob}\left[G_{i,}=1 \mid P_{k}, q_{k}^{*}, c_{j}, c_{k}, \theta_{i j}\right]=\operatorname{Prob}\left[\Delta P_{k}\left(1-\gamma \theta_{i,}\right)-\left(q_{k}^{*}+c_{j}+c_{k}\right)\right]+\varepsilon_{i,}>0\right],{ }^{12}
$$

Rearranging Equation 8 to group variables by subscript yields:

$$
\operatorname{Prob}\left[G_{i_{j}}=1 \mid P_{k}, q_{k}^{*}, c_{j}, c_{k}, \theta_{i_{j}}\right]=\operatorname{Prob}\left[\left(\Delta P_{k}-q_{k}^{*}-c_{k}\right)-\Delta P_{k} \gamma \theta_{i,}-c_{j}+\varepsilon_{i},>0\right]
$$

Consider the NAMCS prescription drug data described in Section 5. For physician $j$, the data can be described as

$$
\left(G_{1,}, G_{2}, \ldots, G_{I}, X_{1}, X_{2}, \ldots, X_{I_{j}}, \tilde{X}_{j}, Y_{j}\right)
$$

where $G_{i}$, denotes whether or not patient $i_{j}$, who was prescribed a multi-source drug, received the generic or trade-name version; $X_{i}$, is a vector of personal characteristics of $i_{j}$ including what type of insurance the patient has; $\tilde{X}_{j}$ is a vector of characteristics of all other patients of physician $j$ who did not receive a multi-source drug; and $Y_{j}$ is a vector of physicianspecific characteristics including the physician's specialty and the state in which the physician practices.

For each patient-visit, the physician recorded demographic characteristics of the patient (age, sex, race, ethnicity) as well as information about the medical condition of the patient. In addition, the physician recorded the names of all medications ordered. Although there are some patients who receive more than one medication, the sample sizes are too small

\footnotetext{
${ }^{12}$ Note that the subscript $k$ has been dropped from $G$ and $\varepsilon$ since, in the empirical analysis, I consider only one prescription per patient.
} 
to make use of these data. For each patient, I therefore consider only the first medicine ordered. Finally, the physician recorded the expected source(s) of payment for the visit: selfpay, medicare, medicaid, blue cross/blue shield, other commercial insurance, HMO/prepaid plans, no charge, or other.

The first thing to note in considering the model in the context of the data is that the model as specified to this point includes prices, but the NAMCS data do not. Furthermore, the model assumes not only that the physician is explicitly price-sensitive, but also that the physician knows the true price differential between the trade-name and generic version of the drug being prescribed. To the extent that the physician does not know true prices of the drugs, $\Delta P_{k}$ is more accurately defined as the physician's expectation of the price differential, which is clearly not known. A measure of the true price differential (such as average list price) is an obvious candidate for a proxy for the expected differential, but incorporating price data into the estimation is left for future research. ${ }^{13}$ Instead, $\left(\Delta P_{k}-q_{k}^{*}-c_{k}\right)$ and $P_{k}$ are treated as unknown drug-specific parameters. In addition, $\theta_{i_{3}}$, the proportion of drug costs covered by insurance, is also not known, although the type of insurance carrier which the patient has is known.

Given an assumption about the distribution of $\varepsilon$ (for instance, that it is normally distributed and independent across individuals), identification of the unknown parameters rests on a choice of which large sample approximation to employ. Since the data exist in multiple dimensions (there are multiple patient and physician observations for a given drug, and multiple drug and patient observations for a given physician), one could consider approximating the finite sample distribution with a variety of different asymptotic approximations, each of which leads to a different estimation strategy. The two most natural asymptotic approximations to consider are $\{J \rightarrow \infty, K$ fixed, $I$ fixed $\}$ and $\{J \rightarrow \infty, K$ fixed, $I$ fixed $\}$. The first of these requires treating $c_{j}$ as a random nuisance parameter, where the result-

\footnotetext{
${ }^{13}$ Incorporating price data into estimation is complicated by the fact that although it seems appropriate to treat physicians as price-takers, prices are still not exogenous in an econometric sense. This is made precise in Kennan (1989).
} 
ing random component in the model, $\left(c_{j}+\varepsilon_{i_{j}}\right)$ is correlated among patients who share the same physician, and may also be correlated with the other covariates of the model. The second of these implies that one could use maximum likelihood to estimate consistently the drug-specific and physician-specific terms, $\left(q_{k}^{*}-c_{k}\right)$ and $c_{j}$, as fixed effects. In other words, $\left(q_{k}^{*}-c_{k}\right)$ and $c_{j}$ could be estimated as coefficients on sets of drug and physician dummy variables, respectively.

Given that the number of physicians (182) is so much larger than the number of patientvisits per physician (which averages approximately 30 ), the empirical results below treat $c_{j}$ as a random parameter. ${ }^{14}$

In estimating Equation 9, I assume that $\varepsilon_{i_{j}}$ is distributed $N\left(\mu_{\varepsilon}, \sigma_{\varepsilon}^{2}\right)$. In addition, $\theta_{i}$, is replaced by a vector of dummy variables indicating the patient's insurance type. Individuals for whom the physician recorded the visit as not being covered by insurance are left as the omitted group. If physicians act as agents for their patients but not for insurers, the resulting coefficients on the insurance dummy variables should be negative. In other words, if there is moral hazard in insurance, physicians will be more likely to prescribe generic drugs to patients who have to pay for their own prescriptions. In addition, when estimating the model, patients who are covered by Blue Cross/Blue Shield or another commercial insurer are aggregated into one insurance group, and the small number of patients whose insurance is specified as "other" or as "no charge" are excluded.

In order to reduce the dimensionality of the drug data, the drug-specific fixed effects in Equation 9 are assumed homogeneous within 20 therapeutic classes of drugs (these classes are listed in Table 3 ). This implies that the quality differential and price differential between trade-names and generics and the cost of information are all the same for drugs within a

\footnotetext{
${ }^{14}$ Heckman (1981b) reports Monte Carlo results of the inconsistency of parameter estimates resulting from a fixed-effect probit model. He finds that for $I_{j} \geq 8$, the bias from the fixed effect probit is small. Estimation results for the patient-specific coefficients obtained from fixed effect probit estimation on the subsample of physicians who treat 8 or more patients are not qualitatively different than those reported below, which are derived from random effects probit estimation.
} 
drug class. This assumption may be reasonable given evidence that physicians do not have full information on drug prices or drug availability. Since there are, however, true price differences across drugs within a given drug class, the implication of this assumption will be addressed in the empirical results. In the estimation, only data from the largest $8 \mathrm{drug}$ classes are used (representing the drug classes with more than 150 patient observations each), since the other twelve drug classes are too small to obtain precise estimates. By reducing to 20 (and to 8 in estimation) the number of drugs with distinct characteristics, it becomes feasible to incorporate drug class-specific dummy variables into the model.

The treatment of the nuisance parameter $c_{j}$ follows in the spirit of Mundlak (1968) and Chamberlain (1980). I assume that $c_{j}$ has a specific functional form:

$$
c_{j}=S_{j} \cdot \pi_{1}+M_{j} \cdot \pi_{2}+T_{j} \cdot \pi_{3}+R_{j} \cdot \pi 4+\bar{X}_{j} \pi_{5}+\nu_{j}
$$

The variables $S, M, T$, and $R$ in Equation 11 are dummy variables which represent observed characteristics of the physician. $S$ is a dummy representing whether the physician is a specialist (i.e. not in general practice or general pediatrics), $M$ and $T$ indicate whether the physician practices in a state with mandatory substitution and two-line prescription pads, respectively, and $R$ is a vector of regional dummies (Northeast, South, West, Midwest).

The parameter $\bar{X}_{j}$ is a (row) vector of the average characteristics of the physician's patients. That is, $\bar{X}_{j}$ has as its elements the percentage of physician $j$ 's patients in each insurance category, the average age of the physician's patients, the percentage of females, the percentage of non-whites, and the percentage of hispanics. These averages include all patients in the NAMCS, including those who were not prescribed any drugs. (Age, sex, race, and ethnicity of each patient are also included as covariates in estimation of Equation 9.)

The random physician component $\nu_{j}$ is assumed to be distributed $N\left(\mu_{\nu}, \sigma_{\nu}^{2}\right)$. This assumption, coupled with that for the individual random component $\varepsilon_{i_{j}}$, leads to an overall random term which, without loss of generality, can be normalized to be distributed $N(0,1)$. Although the model then appears to be that of a simple probit, the correlation across pa- 
tients of a given physician renders probit estimation incorrect. One can treat the usual probit likelihood function as a pseudo-likelihood function (as in Chamberlain, 1984), where consistent estimates of the coefficients of the model can be obtained by maximizing the probit likelihood function, and correcting the standard errors to account for the correlation across patients.

A more efficient estimation strategy, the one used below, is to employ Gaussian Quadrature, which explicitly accounts for the unobserved correlation across patients of a physician by estimating $\rho$, the proportion of the variance in the prescription choice which is physician (but not patient) specific. (Formally, $\rho=\sigma_{\nu}^{2} /\left(\sigma_{\nu}^{2}+\sigma_{\varepsilon}^{2}\right)$ ). In contrast, there is no straightforward way to recover an estimate of $\rho$ by maximizing the usual probit likelihood function since its nonlinearity precludes a simple errors-in-components decomposition. Details of the Gaussian Quadrature procedure are provided in the Technical Appendix. ${ }^{15}$

To recap, the physician prescription choice equation in the form in which it is estimated is:

$$
\begin{array}{ll} 
& \operatorname{Prob}\left[G_{i j}=1 \mid C_{k}, X_{1 i}, X_{2 i}, S_{j}, M_{j}, T_{j}, R_{j}, \bar{X}_{j}\right] \\
=\quad & \operatorname{Prob}\left[C_{k} \lambda+X_{1 i} \beta+C_{k} \cdot X_{2 i} \gamma+S_{j} \cdot \pi_{1}+M_{j} \cdot \pi_{2}+T_{j} \cdot \pi_{3}\right. \\
+ & \left.R_{j} \cdot \pi_{4}+\bar{X}_{j} \cdot \pi_{5}+\nu_{j}+\varepsilon_{i j}>0\right]
\end{array}
$$

where $C$ is a vector containing eight drug class dummy variables; $X_{1}$ is a vector the age of the patient, dummy variables for the sex, race, and ethnicity of the patient; $X_{2}$ is a vector of 4 insurance dummy variables; $\left(\nu_{j}+\varepsilon_{i j}\right)$ is $N(0,1)$; and $S, M, T, R$, and $\bar{X}$ are the elements of the physician-specific fixed effect defined above. The incorporation of $M$ and $T$ linearly

\footnotetext{
${ }^{15} \mathrm{~A}$ final alternative estimation strategy is to assume that $\varepsilon_{i_{j}}$ has a logistic distribution, and to estimate a conditional logit model. The main advantage of the conditional logit model is that, as in the fixed effect probit, no assumption needs to be made as to the distribution of the unobserved physician-specific effect, because it is essentially "differenced out". The conditional logit becomes computationally burdensome for large number of patients per-physician, but estimating the model with random subsamples of the data also yielded coefficient estimates for the patient-specific coefficients similar to those reported below.
} 
in the model assumes that the existence of state legislation promoting generic substitution by pharmacists affects the prescribing habits of physicians across all drugs. For instance, one could interpret an estimated negative coefficient on $M$ as implying that physicians in states with mandatory substitution laws invest less in gaining knowledge about all generics and are therefore less likely to write the generic name on a prescription. If, however, physicians perceive mandatory state substitution laws as eliminating the price differential between generics and trade-name drugs, then the price differential between the two versions of the drug depends on the existence of these laws. This implies that in estimation, the dummy variable $M$ should also be interacted with the vector of insurance variables, $X_{2}$. Both forms of the model are considered below.

\section{Estimation Results}

The results of estimating the prescription choice model Equation 12 are given in Tables $4 \mathrm{a}, 4 \mathrm{~b}$, and $4 \mathrm{c}$. In Tables $4 \mathrm{a}$ and $4 \mathrm{~b}$, I report (solely for the purposes of comparison) results of simple probit estimation (without a standard error correction) along with the results of the Gaussian Quadrature procedure. In Table 4c, only Gaussian Quadrature results are reported. This specification of the model includes 8 drug class dummy variables and a full set of interactions of these class dummy variables with the four insurance status dummy variables. The omitted drug class is Pain Relief and the omitted insurance category is Selfpay. Even with only these eight drug classes, the number of interaction terms is large, so that 53 coefficients are estimated. The sample size is 8579 and the (pseudo) $R^{2}$ from the simple probit is 0.11 . Clearly, there is a lot of variability in the prescription choice decision which the model and the data do not capture. In addition, the estimate of $\rho$ reported in Table $4 \mathrm{a}$ indicates that almost $30 \%$ of the unobserved variance in the prescription choice is physician-specific, rather than patient specific. ${ }^{16}$ In other words, the estimate of $\rho$ implies

\footnotetext{
${ }^{16}$ This implies that the standard errors from the simple probit estimation are too small. Indeed, correcting these standard errors to allow for correlation across patients does increase the probit standard errors.
} 
that some physicians are more prone to prescribing generic drugs than others, and this cannot be explained by the observed characteristics of the physician, the patient, or, to some extent, the drugs prescribed.

Table $4 \mathrm{a}$ also contains the results for the estimated coefficients on the demographic and geographic variables, and the results on the coefficients of the average patient characteristics $\bar{X}_{j}$.

Women are $2.1 \%$ less likely to be prescribed generics (significant at the $5 \%$ level), and non-whites are $3.1 \%$ more likely to receive generics, although this is not significant at standard levels. In addition, older people are significantly less likely to receive generics, even after controlling for their insurance status (which includes Medicare). There are a few possible explanations for these results. The first is that women and older people are more susceptible to potential quality differences between generics and trade-names. For instance, ensuring that elderly patients take their daily medications may require prescribing drugs of a readily identified color and shape. Another possible explanation is that these results are due to heterogeneity in the types of drugs prescribed to these groups versus other groups, and this heterogeneity is not captured by the drug dummy variables. There is some evidence that this is the case. For instance, women are prescribed hormones which have generic substitutes, but these substitutes are seldom prescribed. The third possibility is the demographic variables are proxies for omitted variables such as income of the patient, which may affect the proportion of the cost of the drug that the physician internalizes when prescribing. If, however, physicians internalize more of the cost of drugs for their patients who are poorer, one might expect women to be prescribed generics more often than men. In any case, the magnitude of these effects on the prescription decision is relatively small.

Unlike the results for the unconditional t-tests reported in Section 3, patients in states with two-line prescription pads are only $1.25 \%$ less less likely to receive "generically-written" prescriptions, and this is statistically insignificant. In addition, while these results indicate that physicians in mandatory substitution states are $4.30 \%$ less likely to prescribe generics 
than their colleagues in other states, this is also statistically insignificant. The small and insignificant magnitude of the effect of mandatory substitution laws is particularly interesting in light of the fact that in mandatory substitution states, a physician who writes a prescription for a trade-name version of a drug and does not prohibit substitution by the pharmacist should, in theory, be fairly certain that the pharmacist will substitute and that the patient will receive the generic. The lack of physician sensitivity to state laws has a few possible interpretations. First, to the extent that pharmacist substitution does not appear to occur as frequently as it should, physicians in all states may realize that writing a generic prescription is the only way to ensure that the generic is dispensed. Second, if the prescription decision is made without regard to price or the costs of learning about generics-that is, physicians prescribe generics for reasons such as habit persistence or patient preferencesthen state legislation encouraging substitution by pharmacists will have little bearing on the prescription decision of physicians.

The coefficients on the regional dummy variables indicate that there is significant regional variation in the propensity of generic prescription, with Southerners $8.45 \%$ less likely to receive generics than people in the Northeast. This is consistent with differences in information diffusion across regions, which is the usual explanation of this phenomenon in health care. It is clearly also consistent, however, with any other regional differences in the prescription decision which are not otherwise captured by the model or the data. Considering that there is so much remaining unexplained variation in the prescription choice, making the leap from the estimation results to a conclusion about information diffusion seems premature.

The estimated coefficients on the mean characteristics are all insignificant at $5 \%$ levels, with the exception of the coefficient on percent HMO. Although the interpretation of these mean coefficients can be problematic (see Manski, 1991, for a good discussion of these issues in a slightly different context), the literal interpretation of the coefficient on percent HMO is that, conditional on a patient's insurance status, a patient who switches to a physician with a marginally greater fraction of HMO patients is $10.12 \%$ more likely to receive a generically 
written prescription. There are three possible interpretations of the magnitude and sign of this coefficient. First, because HMOs are heterogeneous in their treatment of pharmacist substitution, it is possible that this figure of $10.12 \%$ is actually downward biased for those HMOs and pre-paid plans who do not mandate pharmacist substitution. Alternatively, as discussed above, it is entirely possible that the emphasis on cost containment in managed care plans makes physicians more sensitive to prescribing generics. Finally, there may be self-selection of low cost physicians into practices which treat patients covered by managed care plans. ${ }^{17}$

Table $4 \mathrm{~b}$ contains the estimation results for the coefficients of the drug dummy variables. There are significant differences across drug classes in the frequency of generic prescription. This corroborates the results in Table 3 and illustrates that the differences in generic prescription across drug classes cannot be attributed solely to measurable characteristics of physicians or their patients.

The results on the tests of agency are given in Table 4c. For each drug class, the table reports the estimated coefficient on each of the insurance dummy variables, the T-statistic and the percent change in the probability of a physician prescribing a generic for a patient who switches from having no insurance to being covered by each of the four insurance categories. The important result in this table is that almost none of the coefficients are estimated precisely, and the directions of the change in generic propensity by insurance class vary greatly across drug classes. That is, the results indicate that there is no strong evidence that the probability of receiving a generic varies systematically with the insurance status of the patient. This contrasts with the raw tabulations reported in Table 2 , which indicated that Medicare patients were significantly less likely than uninsured patients to receive generics and HMO patients were significantly more likely to receive generics than uninsured patients. Controlling for demographic characteristics of a patient and the patient's

\footnotetext{
${ }^{17}$ It should be noted that the most interesting results in Tables $4 \mathrm{a}-4 \mathrm{c}$ are the coefficient estimates on variables which do not vary across patients of a given physician. These variables, of course, do not appear directly in fixed-effect probit estimation or in conditional logit estimation.
} 
physician (in particular, controlling for the age of the patient and the percent of a physician's patient affiliated with an HMO or pre-paid plan), as well as controlling for aggregate drug characteristics effectively eliminates any differentials in generic propensity across insurance classes.

There is thus no evidence of moral hazard in insurance for multi-source prescription drugs. There are, however, a number of caveats to be considered. First, the drug class dummy variables, which interact with the insurance variables, are relatively aggregate. It is therefore possible that there is too much heterogeneity within these drug classes to effectively measure moral hazard which varies across drugs (of a given drug class). Second, there is potential measurement error in the insurance classifications of patients. For example, $15 \%$ of patients in the drug sample are classified as Medicare patients, but most of these patients also have other insurance (see the discussion in Subsection 2.4). Since Medicare does not pay for prescription drugs, classifying all of these patients as being covered by Medicare is potentially problematic. The same problem exists for the large number of patients who are classified as being self-insured. Note, however, that this measurement error is real only if the physician actually knows the patient has other insurance which covers prescription pharmaceuticals. There is some evidence from Medicaid patients that this classification error is not biasing the results. Since physicians bill Medicaid directly for visits by Medicaid patients, and since Medicaid patients do not have other insurance coverage, the classification of Medicaid patients should be accurate. Yet the results for Medicaid patients in Table 4c also vary in sign across drug classes and are predominantly statistically insignificant. The same argument can be made for $\mathrm{HMO} /$ pre-paid patients, where misclassification of insurance status is also quite low. In addition, changing the omitted insurance category does not qualitatively change these results.

Tables $5 \mathrm{a}-\mathrm{c}$ report the estimation results from a regression which excludes all patients eligible for Medicare. This is done for two reasons. The first is to eliminate possible measurement error caused by the misclassification of Medicare patients who have other insurance. 
The second is that Medicare patients, as an older subset of the population, may differ from the rest of the population in their prescription drug needs in a way which is not captured by the linear age term in the model. The sample size for this subsample is 6251 . The results of Tables 5a-c do not differ qualitatively from the results for the entire sample reported in Tables 4a-c. The coefficient on the age variable is lower and even more significant than before. The coefficient on mean age is larger than in Table 4 a but is still insignificant, while the coefficient on percent HMO is slightly lower and less significant.

In order to account for possible measurement error in the mean characteristics variables caused by observing only a subsample of each physician's patients, I also estimated the model for those physicians who record data for more than 20 and, alternatively, 30 patients in the overall NAMCS sample. The results (not reported here) are not substantitively different from those for the full sample, indicating that measurement error in the mean characteristics variables is not causing large biases in the results.

There are two potential reasons to be concerned about the inclusion of state laws in the estimation in Tables $4 \mathrm{a}-4 \mathrm{c}$. As explained above, in states with legislation mandating generic substitution by pharmacists, the effective price differential between generics and trade-name drugs is zero, assuming that pharmacists actually comply with these laws. Since these laws effectively eliminate any price differential between trade-name and generic drugs (when substitution is not prohibited by the physician), the model should set to zero the price differential between trade-name and generic drugs in states with mandatory substitution laws. This would translate into including in estimation a full set of interactions between the mandatory substitution variable and all variables which proxy for price. In addition, the implicit price differential to a physician between prescribing a generic and prescribing a trade-name drug can be manipulated by the physician's choice of whether or not to forbid substitution on the prescription pad. In states with one-line substitution, physicians rarely forbid substitution and therefore rarely manipulate this price differential.

In order to deal with these potential complications to the model which arise in mandatory 
substitution states and two-line prescription pad states, Tables $6 \mathrm{a}-\mathrm{c}$ report the results of model estimated with only the subsample of 4334 observations from states with permissive substitution laws and one-line prescription pads. The results in Tables $6 \mathrm{a}-\mathrm{c}$ are qualitatively similar to those for the full sample reported in Tables 4 a-c. In particular, the results in Table $6 \mathrm{c}$ indicate that even in states without mandatory substituion, there is no discernable moral hazard in insurance.

\section{Conclusion}

This paper examines why physicians continue to prescribe trade-name drugs even when less expensive generic substitutites are available. I use a data set on physicians, their patients, and the multi-source drugs prescribed to study the prescription habits of physicians in prescribing generic and trade-name drugs. The results indicate that almost all physicians prescribe both types of drugs to their patients. There does appear, however, to be persistence in the prescription behavior of physicians. Patients who are treated by physicians with large numbers of HMO or pre-paid patients are more likely to be prescribed generics, and there is regional variation in the propensity of physicians to prescribe generic drugs which cannot be explained by other observable characteristics of the physicians or their patients. In addition, there is a great deal of heterogeneity across drugs in the penetration of generics.

Very little of the prescription decision can be explained by observable characteristics of patients. While the results indicate that older patients and women are significantly less likely to be prescribed generics, the magnitudes of these differences are small.

Physicians do not appear to respond to the pecuniary incentives of state legislation in prescribing drugs. Physicians in states which mandate generic substitution by pharmacists seem no less likely to write generic presctiptions than physicians in other states. In addition, there is no evidence in prescription behavior of moral hazard in insurance. Patients with private insurance are no less likely to receive generics than others, conditional on other 
observable personal characteristics and characteristics of the prescribing physician.

Physicians appear to repeatedly prescribe the same version of a given drug. This behavior is heterogeneous across physicians and across drugs. There are two possible explanations for this. Physicians may be determining the efficacy of generics for each of the drugs they prescribe and then using those determinations for all of their patients. Alternatively, physicians may not explicitly evaluate quality differentials at all, but rather persist in prescribing a certain version of each drug simply out of habit. The empirical analysis presented here cannot distinguish between these two explanations. However, given that most of the persistence in prescription behavior cannot be explained by observable demographic characteristics of the patients and the physicians, and given that physicians do not appear to respond to the pecuniary incentives embodied in state substitution laws, it is difficult to imagine that physicians are truly making complex utility-maximizing decisions when they prescribe drugs. Habit therefore seems the most likely explanation for the unobserved persistence of prescription behavior.

The results presented here raise as many questions as they answer, leaving much room for future research. First, because the drug class dummy variables are significant in all estimation results, it seems clear that the issue of generic prescription could benefit from the use of a formal treatment of information diffusion. One possibility for incorporating a measure of information diffusion into the estimation is to gather data on the length of time a generic has been marketed. Although the issues involved in collecting those data are too many to mention here, the incorporation of some time dimension into the data would be beneficial.

As mentioned above, actual price data on the differential in price between trade-name and generic drugs could be incorporated sensibly into estimation to more precisely account for the differences across drugs in physicians' perception of the cost savings of generics. It is possible that the inconclusive results in these tables on moral hazard in insurance are a product of utilizing aggregate drug dummy variables in estimation rather than incorporating data on 
the price differentials between generic and trade-name drugs. This will be explored in future research. The evidence presented in Section 3 and in Section 6, however, points to the fact that physicians do not respond to pecuniary incentives when prescribing. Physicians appear to persist in prescribing a given version of a drug to all patients, regardless of their insurance, but this persistence varies across physicians and across drugs. In addition, physicians in mandatory substitution states are no more likely to prescribe generics, although these laws should change the pecuniary incentives involved in the prescription decision. For these reasons, it seems unlikely that the incorporation of price data will yield results consistent with moral hazard in insurance.

Another element in the examination of the diffusion of generics would be to combine data from the NAMCS surveys in other years. Unfortunately, the NCHS has not yet released physician identifying data for years other than 1989 , so this cannot be incorporated immediately. Finally, the results might be aided by more accurate reporting in the NAMCS of insurance payments.

What is clear from the results presented here is that there are potentially large social costs due to the habitual prescription of trade-name drugs. When physicians make prescription decisions based on their idiosyncratic habits or the habits of others around them, they do not make cost-effective decisions. Moreover, state legislation which encourages generic substitution does not affect physician prescription decisions. Future changes in the structure of the health care system may, however, increase the frequency of generic prescription. If the increased propensity of HMO-affiliated physicians to prescribe generic drugs is due to the emphasis on cost-containment in HMOs, national health insurance based on managed care plans may dramatically increase the demand for generic drugs. There is one important caveat to the potential social benefits of increased generic prescription. Reducing the returns to trade-name drugs may have an adverse effect on pharmaceutical $R \& D$ investment and new drug development. There is little evidence on the magnitude of this effect, which suggests another important avenue for future research. 


\section{Data APPENDIX}

The data are taken from three versions of the 1989 NAMCS: the publicly available NAMCS for Patient-Visits; a version of the NAMCS for Patient-Visits with additional confidential identifying information; and the publicly available NAMCS for Drug Mentions. The NAMCS is a survey of approximately 1200 office-based physicians and a subsample of their patients which is conducted not-quite annually by the National Center for Health Statistics (NCHS). It is a three stage sample of primary sampling units (PSUs), physician practices within a PSU, and patient visits within practices. A PSU is a county, group of counties, or standard metropolitan statistical area. After the first and second stages of the sample, selected physicians were randomly assigned to a week of the year beginning in February 1989 , and filled out detailed questionaires on a random subsample of patient-visits during that week. (Physicians who saw less than 10 patients filled out questionaires for all patients they saw).

These questionaires contain data on demographic characteristics of the patient (age, sex, race, ethnicity) as well as data pertaining to the medical condition of the patient and details about what occurred during the visit such as duration of the visit, procedures performed, and diagnosis. In addition, the physician recorded for each patient the expected source(s) of payment for the visit: self-pay, medicare, medicaid, blue cross/blue shield, other commercial insurance, $\mathrm{HMO}$ /prepaid plans, no charge, or other. If the patient paid for the visit but was to be reimbursed by a third party payer, the physician was told to only consider the third party payer as the source of payment. Most importantly, the physician was instructed to list up to five medications ordered for the patient and to record "the same specific drug name (brand or generic)...used on any prescription." The definition of medications was interpreted broadly and included both prescription and non-prescription pharmaceuticals.

All three versions of the data contain the results of the questionaires as well as information identifying the specialty of the physician and the region of the country in which the physician practices (North, South, East, Midwest). In the publicly available NAMCS for Patient-Visits 
and its confidential counterpart, the unit of observation is a patient-visit and patient-specific sampling weights are included in the data. The confidential NAMCS also links the patients of each physician together via a physician identification number and contains information on the U.S. state in which the physician practiced. The state identifiers allow prescriptions to be classified according to state laws about generic substitution, and the physician identifiers allow for the inclusion of physician-specific fixed effects into the model. Although the public version of the NAMCS is available for other years as well, the confidential version of the data has only been prepared for 1989.

In the NAMCS for Drug Mentions, the unit of observation is an ordered medicine. Therefore, information is only included for those patients for whom a drug was ordered, and for those patients for which multiple medicines were ordered, multiple observations appear (and these observations cannot be linked in these data). Because the Drug-Mentions data focuses on medicines, drug-specific sampling weights are attached to each observation. In addition, these data contain information matching each ordered medicine to a unique trade-name drug code as well as a corresponding generic drug code. The data also include other information about the drug ordered such as the generic name, manufacturer (either generic or tradename), prescription status (over-the-counter or prescription), and drug class code (one of 20 major classes such as opthalmics or neurologics). ${ }^{18}$ In conversations with representatives at the NCHS, it became clear that the manufacturer codes for each drug are not entirely reliable. I therefore verified each manufacturer code using the 1991 Drug Facts and Comparisons, a comprehensive pharmaceutical industry source for drug information.

The two sources of sampling weights in the data are the patient weights from the NAMCS for Patient-Visits and the drug weights from the Drug Mentions data. Experimentation with these two sets of sampling weights yielded very little difference between unweighted and weighted estimates of any of the results in this paper. All results reported here are derived without sampling weights.

\footnotetext{
${ }^{18}$ See Table 3 for a list of drug codes.
} 


\section{TECHNICAL APPENDIX}

\section{The Full Likelihood for the Random Effects Probit}

Consider the NAMCS prescription drug data. For physician $j$, the data can be described as

$$
\left(G_{1_{j}}, G_{2_{j}}, \ldots, G_{I_{j}}, Z_{1}, Z_{2,}, \ldots, Z_{I_{j}}, Z_{j}\right)
$$

where $G_{i}$, denotes whether or not patient $i_{j}$, who was prescribed a multi-source drug, received the generic or trade-name version and $Z_{i_{j}}$ is a vector of personal characterisitcs of the physician, the patients who received multi-source drugs, and patients who did not receive a multi-source drug. Define $\rho=\sigma_{\nu}^{2} /\left(\sigma_{\nu}^{2}+\sigma_{\varepsilon}^{2}\right)$, where $\sigma_{\nu}^{2}$ and $\sigma_{\varepsilon}^{2}$ are defined as in Section 5, and define $\delta$ to be the vector of parameters to be estimated in Equation 12. Then joint probability of the prescription decision physician $j$ makes for all $I_{j}$ patients, conditional on observables and conditional on the unobservable $\sigma_{\nu}$, is:

$$
\begin{aligned}
& \operatorname{Prob}\left(G_{1_{j}}, \ldots, G_{i_{j}} \mid Z_{1_{j}}, \ldots, Z_{I_{j}}, \delta, \rho, \sigma_{\nu}\right) \\
& =\prod_{i_{j}=1}^{I_{j}} \Phi\left(\left(Z_{i_{j}} \delta /(1-\rho)^{1 / 2}+(\rho /(1-\rho))^{1 / 2} \nu_{j}\right)\left(2 G_{i_{j}}-1\right)\right) .
\end{aligned}
$$

The unconditional (on $\nu_{j}$ ) likelihood for the problem is

$$
\begin{aligned}
& L(\delta, \rho)=\prod_{j=1}^{J} \int_{-\infty}^{\infty} 1 / \sqrt{(2 \pi) e^{-\nu_{j} / 2} .} \\
& \prod_{i_{j}=1}^{I_{j}} \Phi\left(\left(Z_{i_{j}} \delta /(1-\rho)^{1 / 2}+(\rho /(1-\rho))^{1 / 2} \nu_{j}\right)\left(2 G_{i_{j}}-1\right)\right) \partial \nu_{j} .
\end{aligned}
$$

Notice that the likelihood contains only a one-dimensional integral rather than the standard $I_{j}$ dimensional integral of the multinomial probit. The reduction in dimensionality arises from the assumption that the errors across patients of a given physician are equicorrelated. This assumption is natural in this context because the patient data are essentially just 
multiple observations for each physician. That is, the patient data have no natural ordering such as a time dimension. ${ }^{19}$

\section{Gaussian Quadrature}

Butler and Moffitt (1982) point out that for the type of likelihood likelihood function specificed in Equation 15, Gaussian Quadrature, an efficient numerical integration procedure, can be used to evaluate the integral with high accuracy and relatively low computational cost.

The key to using Gaussian Quadrature in this case is the Hermite Integration formula (see, for example, Press, et. al, 1986):

$$
\int_{-\infty}^{\infty} e^{-Z^{2}} g(Z) d Z=\sum_{p=1}^{P} w_{p} g\left(Z_{p}\right)
$$

where $P$ is the number of points at which the integral is evaluated, $w_{p}$ is the weight given to the $p$ th point, and $g\left(Z_{p}\right)$ is the function $g(Z)$ evaluated at $Z_{p}$. Any likelihood function containing a one-dimensional integral of the form in Equation 16 can be expressed in discrete terms of a summation over evaluation points.

Taking the $\log$ of the likelihood function in Equation 15, defining $\tilde{\nu}=\nu / \sqrt{2}$, and using the Hermite Integration formula transforms the estimation problem for $\delta$ into a Gaussian Quadrature maximum likehood problem of the form:

$$
\begin{aligned}
\max _{\delta} & \sum_{j=1}^{J} \ln \sum_{p=1}^{P} 1 / \sqrt{\pi} w_{p} . \\
& \prod_{i,=1}^{I_{j}} \Phi\left(\left(Z_{i} \delta /(1-\rho)^{1 / 2}+\sqrt{\left.\left.(2)(\rho /(1-\rho))^{1 / 2} \tilde{\nu}_{p}\right)\left(2 G_{i,}-1\right)\right) .}\right.\right.
\end{aligned}
$$

Given weights $w_{p}$ and evaluation points $\tilde{\nu_{p}}$ (which can be found in Abramowitz and Stegun, 1964), solving for $\hat{\delta}$ in Equation 17 is a typical maximization problem. The Gaussian Quadrature results reported in the paper were calculated using 20 evaluation points.

\footnotetext{
${ }^{19}$ If the data were ordered, one could relax the equicorrelation assumption. In that case, the dimensionality of the problem could not be reduced, and a feasible estimation strategy would involve using the Method of Simulated Moments. See Keane (1994) and the references therein for details.
} 


\section{REFERENCES}

Abramowitz, M. And I. Stegun, (1964), Handbook of Mathematical Functions with Formulas, Graphs, and Mathematical Tables. National Bureau of Standards Applied Mathematics Seris No. 55. Washington D.C.: U.S. Government Printing Office.

Berndt, E.R., Z. Griliches, And J.G. Rosett, (1991), "On the Accuracy of Producer Price Indexes for Pharmaceutical Preparations: An Audit Based on Detailed Firm-Specific Data." NBER Working Paper No. 3490.

The Boston Consulting Group, Inc., (1993), "The Changing Environment for U.S. Pharmaceuticals." The Boston Consulting Group, mimeo.

Butler, J.S. AND R. MoffitT, (1982), "A Computationally Efficient Quadrature Procedure for the One-Factor Multinomial Probit Model," Econometrica, vol. 50, pp. 761-764.

Caves, R., M. Whinston, And M. Hurwitz, (1991), "Patent Expiration, Entry, and Competition in the U.S. Pharmaceutical Industry," Brookings Papers on Economic Activity, 1991 Annual, pp. 1-66.

Chamberlain, G., (1980), "Analysis of Covariance with Qualitative Data," Review of Economic Studies, 47: 225-238.

Chamberlain, G., (1984), "Panel Data," in Handbook of Econometrics, vol II, edited by Z. Griliches and M. Intriligator, pp. 1247-1318. Amsterdam: North-Holland.

Doering, Paul L., Wayne L. Russell, William C. McCormick, and Deborah L. KLAPP, (1988), "Therapeutic Substitution in the Health Maintenance Organization Outpatient Environment," Drug Intelligence and Clinical Pharmacy, vol. 22, pp. 125-130.

Dranove, D., (1989), "Medicaid Drug Formulary Restrictions," Journal of Law \& Economics, vol. XXXII, April, pp. 143-162.

Drug Facts and Comparisons, (1991). St. Louis: J.P. Lippincott Company. 
Drug Topics, (1990), "National Audit Finds Drug Substitution Rate Steady," June 4, pp. 12-14.

Feldstein, M., (1976), "Seven Principles of Social Insurance," Challenge, November/December, pp. 6-11.

Frank, R.G. and D.S. Salkever, (1991), "Pricing, Patent Loss and the Market for Pharmaceuticals," Southern Economic Journal, vol. 59, October, pp. 165-180.

Grabowski H. and J. Vernon, (1990), "Brand Loyalty, Entry and Price Competition in Pharmaceuticals after the 1984 Drug Act," Journal of Law and Economics, vol. 35, no. 2, October, pp. 331-350.

Griliches, Z. And I. Cockburn, 1993, "Generics and New Goods in Pharmaceutical Price Indexes," National Bureau of Economic Research Working Paper No. 4272.

Heckman, J.J., (1981), "Statistical Models for Discrete Panel Data," in Structural Analysis of Discrete Data With Econometric Applications, edited by C. Manski and D. McFadden, pp. 114-178.

Heckman, J.J., (1981a), "The Incidental Parameters Problem and the Problem of Initial Conditions in Estimating a Discrete Time-Discrete Data Stochastic Process," in Structural Analysis of Discrete Data With Econometric Applications, edited by C. Manski and D. McFadden, pp. 179-195.

Keane, M.P., (1994), "A Computationally Practical Simulation Estimator for Panel Data," Econometrica, vol 62, pp. 95-116.

Kennan, J., (1989), "Simultaneous Equations Bias in Disaggregated Econometric Models," Review of Economic Studies, Vol. 56, pp. 151-156.

Luft, H.S., (1987), Health Maintenance Organizations. New Brunswick: Transaction Books. 
Masson, A. And R. L. Steiner, (1985), Generic Substitution and Prescription Drug Prices: Economic Effects of State Drug Product Selection Laws, Staff Report of the Bureau of Economics, U.S. Federal Trade Commission. Washington, D.C.: Federal Trade Commision.

Mundlak, Y. (1978), "On the Pooling of Time Series and Cross Section Data," Econometrica 46:69-85.

New York Times, (1989), "Safety Questions Raised About Generic Drugs," September 9.

Newhouse, J., (1992), "Medical Care Costs: How Much Welfare Loss," The Journal of Economic Perspectives, Vol. 6, Number 3, pp. 3-21.

Newhouse, J.P., (1993), Free for All?. Cambridge, MA: Harvard University Press.

PhelPS, C.E., (1992), "Diffusion of Information in Medical Care," The Journal of Economic Perspectives, Vol. 6, Number 3, pp. 23-42.

Press, W.H., B.P. Flannery, S.A. Tuekolsky, and W.T. Vetterling, (1986), $\mathrm{Nu}$ merical Recipes: The Art of Scientific Computing, New York: Cambridge University Press.

Sнан, H. (1992). "Generic Drugs: Catalysts for Change in the Pharmaceutical Industry," mimeo, Decisions Resources, Inc.

Temin, P., (1980), Taking Your Medicine, Cambridge, MA: Harvard University Press.

U.S. Congress, Office of Technology Assessment, (1993), Pharmaceutical RBD: Costs, Risks and Rewards, OTA-H-522. 
Figure 1.

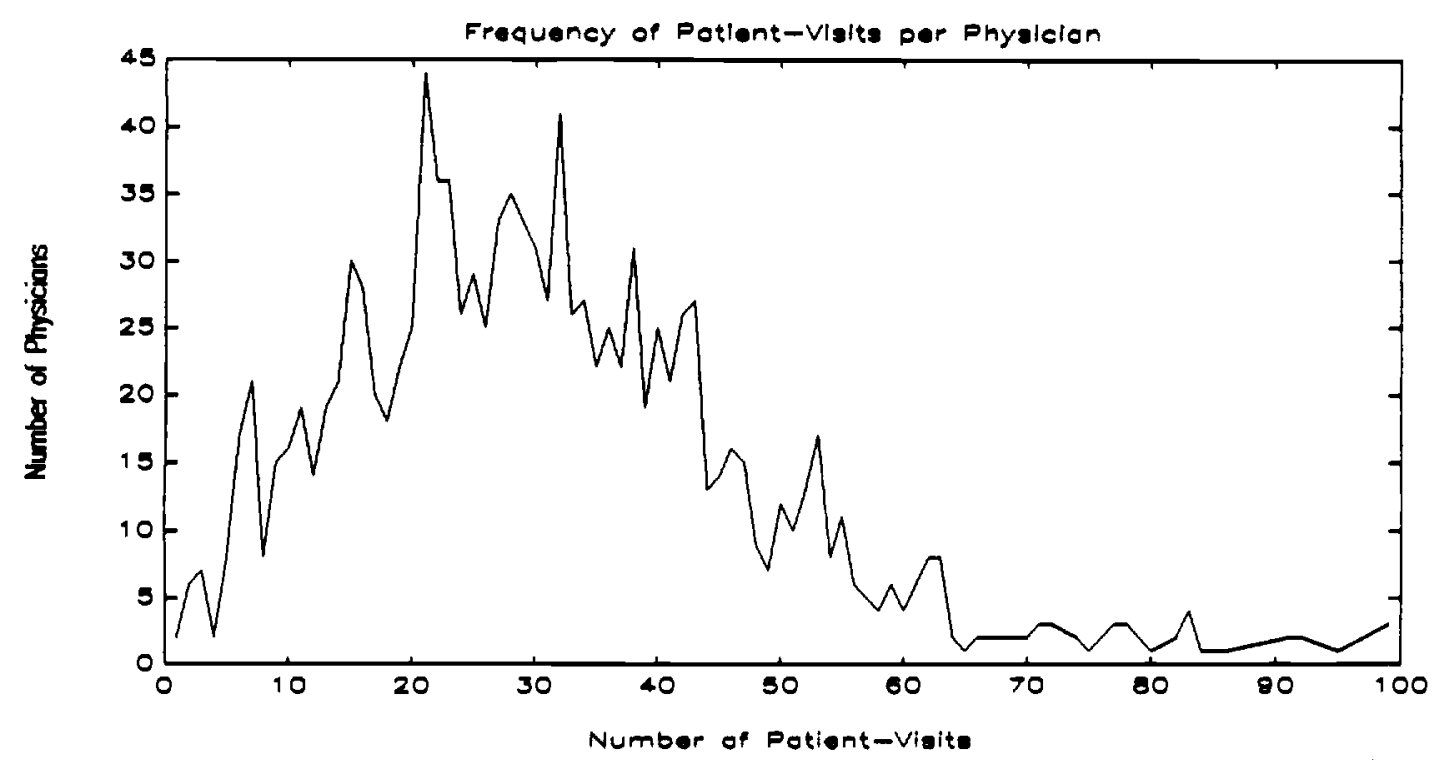


Figure 2.

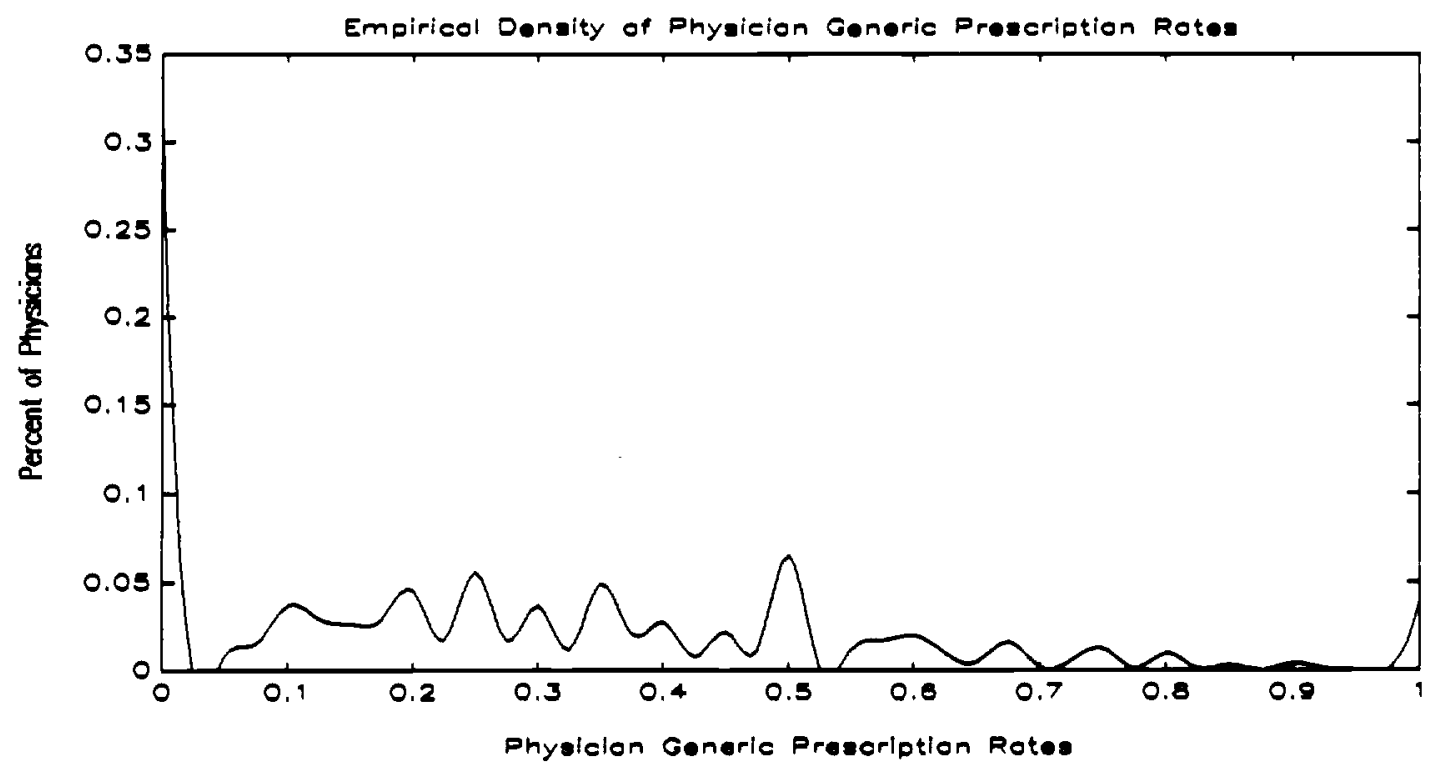

Figure 3.

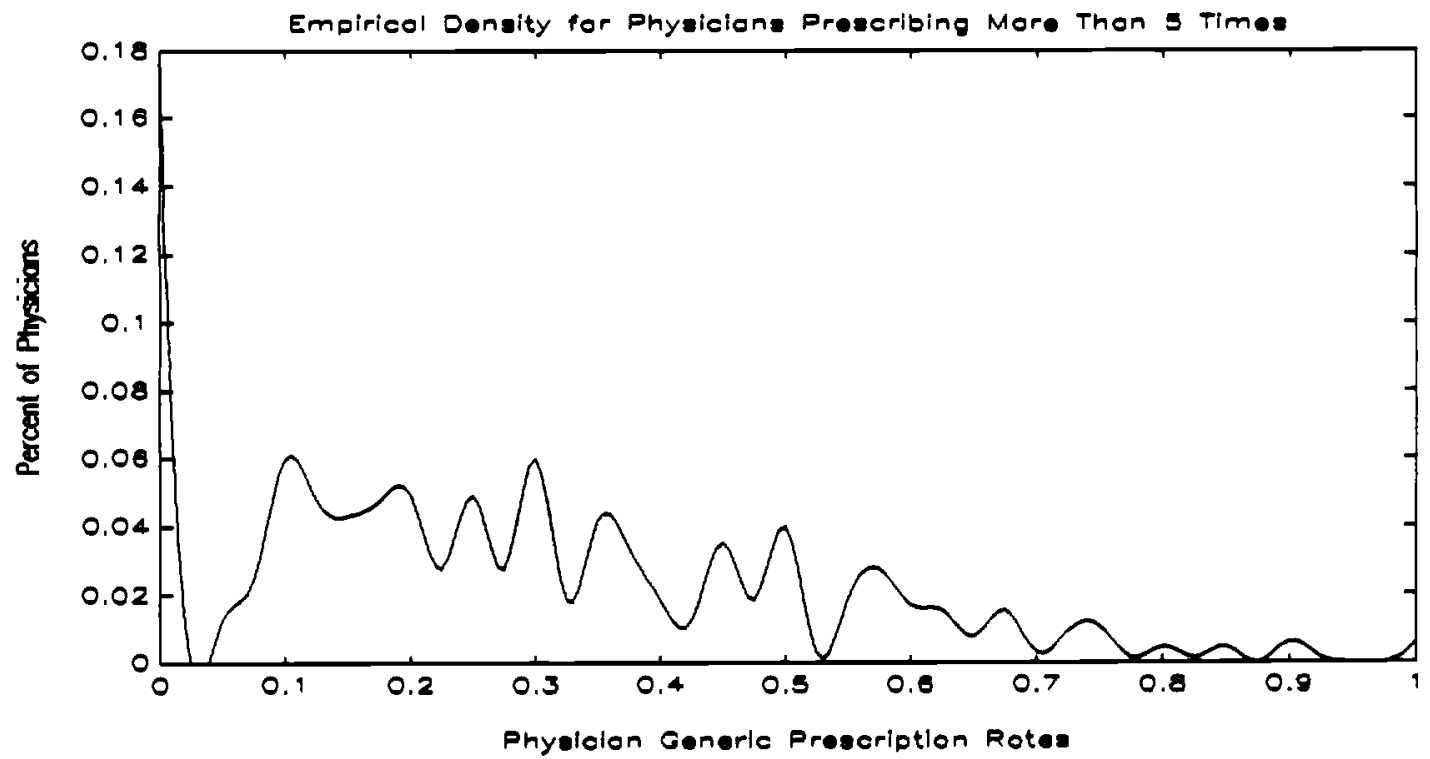


Figure 4

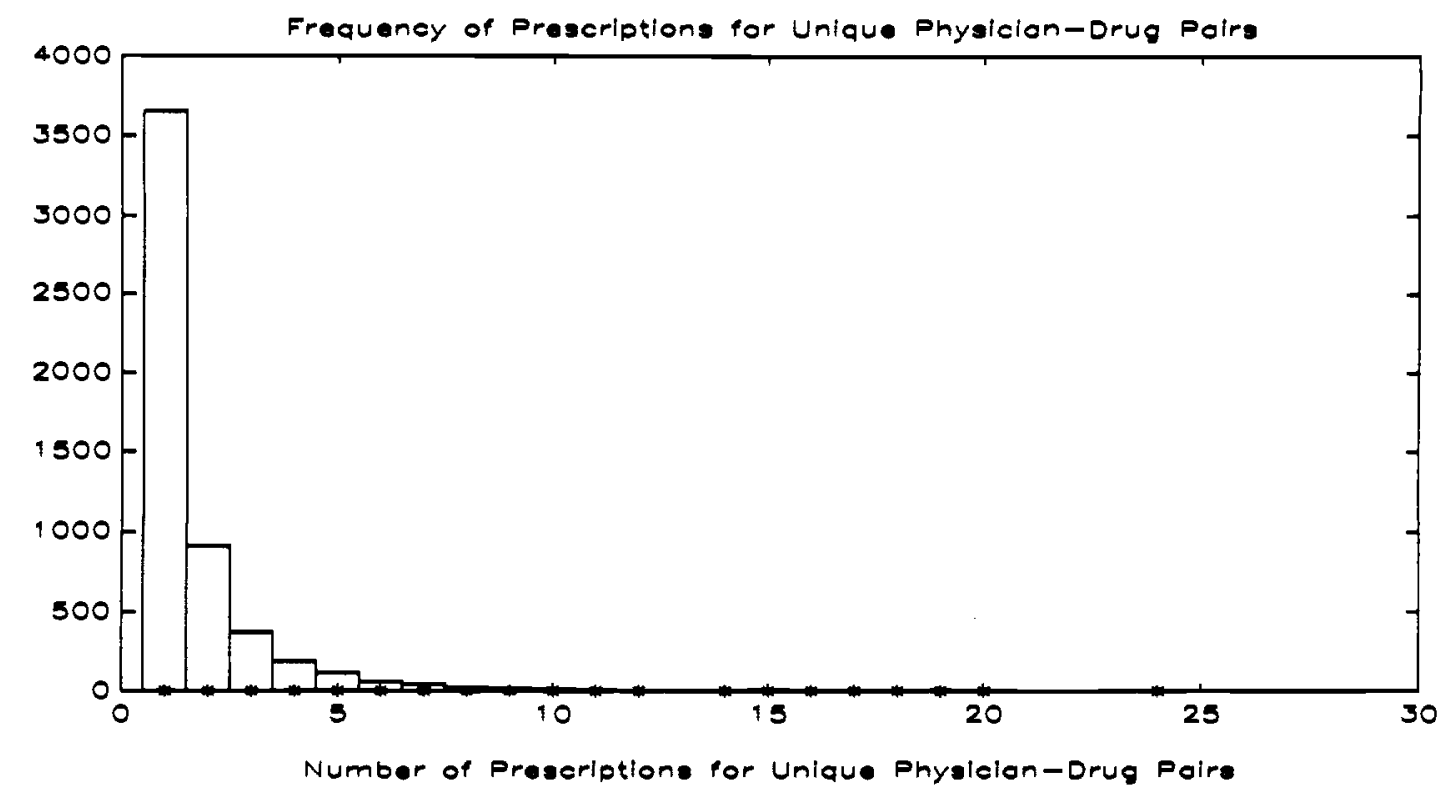

Figure 5

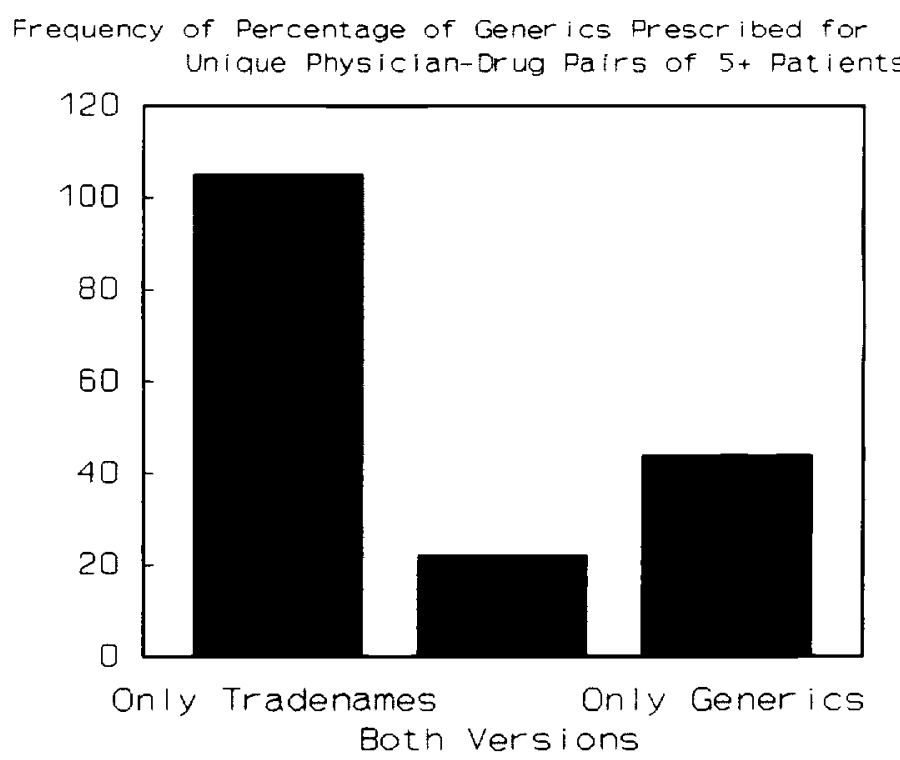


Table 1. Summary Statistics for Overall NAMCS Patient Sample

\begin{tabular}{||lrr||}
\hline \multicolumn{1}{|c}{ Variable } & Mean & Std. Dev. \\
\hline \hline Age & 42.39365 & 24.99251 \\
Female & 0.59748 & 0.49041 \\
Non-White & 0.10669 & 0.30872 \\
Hispanic & 0.05281 & 0.22366 \\
Selfpay & 0.27284 & 0.44543 \\
Medicare & 0.14429 & 0.35138 \\
Medicaid & 0.07553 & 0.26424 \\
Blue Cross/Blue Shield & 0.12660 & 0.33253 \\
Other Commercial Insurer & 0.24076 & 0.42755 \\
HMO/Pre-Paid Plan & 0.13999 & 0.34698 \\
Specialist & 0.55479 & 0.49700 \\
Northeast & 0.18969 & 0.39206 \\
Midwest & 0.25884 & 0.43801 \\
South & 0.33965 & 0.47360 \\
West & 0.21182 & 0.40860 \\
\hline \hline
\end{tabular}

The sample size is 32,796 . This includes only those observations for which valid data for each variable were available. Medicare patients are those for whom the physician recorded the patientvisit as being paid for solely by Medicare. Patients who were not charged by the physician for the visit are excluded. Specialist are physicians who are not in general practice, family practice, or basic pediatrics. 
Table 2. Frequency of Generic Prescription by Insurance Carrier

\begin{tabular}{||lcc||}
\hline Insurance Carrier & Number of Obs. & \% Generic \\
\hline Selfpay & 2846 & 28.53 \\
Medicare & 1394 & 21.80 \\
Medicaid & 871 & 29.74 \\
Blue Cross/Other Private & 2993 & 26.96 \\
HMO/Pre-paid & 1213 & 32.07 \\
\hline
\end{tabular}

Note: T-tests of the equality of each of the insurance classes with Selfpay indicate that only HMO and Medicare are significantly different than Selfpay at the $5 \%$ level. Medicare includes those patients for whom the physician recorded the patient-visit as being paid for solely by Medicare. If another insurance carrier was recorded in addition to Medicare, that other insurance carrier was assigned to the patient. 
Table 3: Frequency of Generic Prescription by Drug Class

\begin{tabular}{||llcc||}
\hline & Name of Class & Obs & \% Generics \\
\hline \hline & All Drugs & 9317 & 27.59 \\
\hline \hline BY DRUG CLASS & & \\
\hline 1 & Anesthetics/Adjuncts & 15 & 60.00 \\
3 & Antimicrobials & 3495 & 40.54 \\
4 & Hematologics & 81 & 9.87 \\
5 & Cardiovascular-renals & 1275 & 20.63 \\
6 & Central Nervous System & 681 & 28.34 \\
7 & Radiopharmaceuticals/Contrast & 4 & 100.00 \\
& Media & & \\
8 & Gastrointestinals & 166 & 3.61 \\
9 & Metabolics/Nutrients & 64 & 25.00 \\
10 & Hormones/Hormonal & 927 & 39.27 \\
& mechanisms & & \\
12 & Skin/Mucous Membranes & 561 & 5.70 \\
13 & Neurologics & 214 & 1.87 \\
14 & Oncolytics & 92 & 79.35 \\
15 & Ophthalmics & 415 & 12.05 \\
16 & Otics & 48 & 0.00 \\
17 & Pain Relief & 793 & 12.74 \\
18 & Antiparasitics & 31 & 0.03 \\
19 & Respiratory Tract & 432 & 6.02 \\
20 & Miscellaneous & 23 & 17.39 \\
\hline
\end{tabular}


Table 4a. Estimated Coefficients on Demographic Variables, Geographic Variables, and Average Characteristics for Full Sample

\begin{tabular}{|c|c|c|c|c|c|}
\hline Variable & $\begin{array}{c}\text { Simple } \\
\text { Probit } \\
\text { Coefficient }\end{array}$ & $\begin{array}{c}\text { Simple } \\
\text { Probit T- } \\
\text { statistic }\end{array}$ & $\begin{array}{c}\text { Random } \\
\text { Effects } \\
\text { Probit } \\
\text { Coefficient }\end{array}$ & $\begin{array}{c}\text { Random } \\
\text { Effects } \\
\text { Probit T- } \\
\text { statistic }\end{array}$ & $\begin{array}{l}\text { \% Change } \\
\text { in Generic }\end{array}$ \\
\hline Constant & -1.0788 & -7.1653 & 0.8967 & -5.1508 & \\
\hline Age & -0.0041 & -4.1919 & -0.0033 & -3.7247 & $-0.10 \%$ \\
\hline Female & -0.0687 & -2.1271 & -0.0686 & -2.3467 & $-2.11 \%$ \\
\hline Non-White & 0.1124 & 1.7728 & 0.0997 & 1.8264 & $3.12 \%$ \\
\hline Hispanic & -0.0198 & -0.2337 & -0.0228 & -0.1816 & $-0.70 \%$ \\
\hline Specialist & 0.0271 & 0.7606 & 0.0229 & 0.4037 & $0.70 \%$ \\
\hline Mandatory Substitution & -0.0953 & -2.0123 & -0.1432 & -1.8961 & $-4.30 \%$ \\
\hline Twoline Prescription & -0.0385 & -1.0528 & -0.0409 & -0.7192 & $-1.25 \%$ \\
\hline Mean Age & 0.0032 & 2.2053 & 0.0030 & 1.4514 & $0.09 \%$ \\
\hline Percent Female & 0.0765 & 0.7175 & -0.1329 & -0.9097 & $-4.08 \%$ \\
\hline Percent Black & 0.0892 & 0.8413 & 0.0771 & 0.5000 & $2.37 \%$ \\
\hline Percent Hispanic & -0.0790 & -0.5914 & -0.1560 & -0.8127 & $-4.79 \%$ \\
\hline Percent Medicaid & 0.0461 & 0.3075 & 0.1963 & 0.9011 & $6.03 \%$ \\
\hline Percent Medicare & -0.0416 & -0.2912 & 0.1090 & 0.4776 & $3.29 \%$ \\
\hline Percent Private & 0.0145 & 0.1762 & 0.0667 & 0.6005 & $2.05 \%$ \\
\hline Percent HMO/Pre-Paid & 0.2914 & 2.8172 & 0.3293 & 2.3169 & $10.12 \%$ \\
\hline Midwest & -0.1649 & -2.8668 & -0.1833 & -1.9166 & $-5.80 \%$ \\
\hline South & -0.2717 & -5.0343 & -0.2727 & -3.0446 & $-8.45 \%$ \\
\hline West & -0.0228 & -0.3973 & -0.0158 & -0.1679 & $-0.52 \%$ \\
\hline$\rho$ & & & 0.2912 & 14.8545 & \\
\hline
\end{tabular}

Note: The dependent variable is 1 if the generic is prescribed, 0 otherwise. The sample size is 8579 . The Mean and Percent Variables refer to the mean and percent charateristics of the physician whom the patient visits. The omitted region category is Northeast. The omitted insurance categories are Selfpay and Percent Selfpay. The percent changes in generic prescription are calculated as the average over the sample of the percent change in the probability of receiving a generic. For example, the percent change in the probability of generic prescription for age is the average percentage change for a marginal increase in age. For the dummy variables, the percent change in generic prescription represents the average percentage change that occurs when a person moves into the category represented by the dummy variable. The parameter $\rho$ is the estimated variance of the random physician effect. 
Table 4b. Estimated Coefficients for Drug Class Dummy Variable for Full Sample

\begin{tabular}{|c|c|c|c|c|c|}
\hline Drug Class & $\begin{array}{c}\text { Simple } \\
\text { Probit } \\
\text { Coefficient }\end{array}$ & $\begin{array}{c}\text { Simple } \\
\text { Probit T- } \\
\text { Statistic }\end{array}$ & $\begin{array}{c}\text { Random } \\
\text { Effects } \\
\text { Probit } \\
\text { Coefficient }\end{array}$ & $\begin{array}{l}\text { Random } \\
\text { Effects T- } \\
\text { Statistic }\end{array}$ & $\begin{array}{c}\% \\
\text { Change } \\
\text { in } \\
\text { Generic }\end{array}$ \\
\hline Antimicrobials & 0.9836 & 7.7664 & 0.8695 & 8.2921 & $26.67 \%$ \\
\hline Cardiovascular/Renals & 0.4862 & 3.1287 & 0.4057 & 3.0865 & $10.59 \%$ \\
\hline Central Nervous System & 0.7565 & 5.0134 & 0.4928 & 4.0800 & $13.33 \%$ \\
\hline $\begin{array}{l}\text { Hormones/Hormone } \\
\text { Mechanisms }\end{array}$ & 0.9334 & 6.5001 & 0.8311 & 7.1507 & $25.23 \%$ \\
\hline Skin/Mucous Membrane & -0.6307 & -3.0174 & -0.7175 & -4.4059 & $-10.04 \%$ \\
\hline Ophthalmics & -0.1636 & -0.7434 & -0.2133 & -0.8963 & $-4.07 \%$ \\
\hline Respiratory Tract & -0.4207 & -1.9258 & -0.4495 & -2.6543 & $-7.47 \%$ \\
\hline
\end{tabular}

Note: The Omitted Drug Category is Pain Relief. 
Table 4c: Tests of Moral Hazard for the Full Sample

Equality of Individual Insurance Variables With Self-Payment

Random Effects Probit Results

\begin{tabular}{|c|c|c|c|c|c|c|c|c|c|}
\hline $\begin{array}{l}\text { Insurance } \\
\text { Variable }\end{array}$ & & $\begin{array}{c}\text { Anti- } \\
\text { Microbials }\end{array}$ & $\begin{array}{l}\text { Cardio- } \\
\text { vasucular }\end{array}$ & Metabolics & Hormones & $\begin{array}{c}\text { Skin/Mucous } \\
\text { Membranes }\end{array}$ & Opthalmics & $\begin{array}{l}\text { Pain } \\
\text { Relief }\end{array}$ & $\begin{array}{c}\text { Respiratory } \\
\text { Tract }\end{array}$ \\
\hline \multirow[t]{3}{*}{ Medicaid } & Coefficient & -0.0495 & 0.2454 & -0.1352 & 0.3186 & 1.0402 & 0.2870 & -0.4189 & -0.0217 \\
\hline & T-Statistic & -0.6253 & 1.5590 & -0.7719 & 1.7792 & 5.3204 & 1.0178 & -1.5254 & -0.0925 \\
\hline & $\%$ Change & $1.88 \%$ & $-8.21 \%$ & $4.25 \%$ & $-12.40 \%$ & $-18.69 \%$ & $-5.80 \%$ & $7.18 \%$ & $0.26 \%$ \\
\hline \multirow[t]{3}{*}{ Medicare } & Coefficient & -0.1811 & 0.0161 & 0.0337 & 0.3394 & -0.1318 & 0.2362 & 0.0374 & 0.1240 \\
\hline & T-Statistic & -1.7307 & 0.1409 & 0.2367 & 2.6833 & -0.3801 & 0.9270 & 0.2085 & 0.4694 \\
\hline & $\%$ Change & $6.46 \%$ & $-0.50 \%$ & $-1.12 \%$ & $-13.22 \%$ & $0.94 \%$ & $-4.63 \%$ & $-1.83 \%$ & $-1.66 \%$ \\
\hline \multirow[t]{3}{*}{ Private } & Coefficient & -0.0646 & -0.2823 & -0.0775 & -0.1486 & 0.2184 & 0.1237 & 0.1993 & 0.0010 \\
\hline & T-Statistic & -1.0828 & -2.4816 & -0.6827 & -1.4649 & 1.1352 & 0.4222 & 1.5740 & 0.0041 \\
\hline & \% Change & $2.45 \%$ & $7.89 \%$ & $2.48 \%$ & $5.51 \%$ & $-2.12 \%$ & $-2.27 \%$ & $-4.81 \%$ & $-0.01 \%$ \\
\hline \multirow[t]{3}{*}{ HMO/Pre-Paid } & Coefficient & -0.0644 & -0.0734 & -0.2393 & 0.0426 & 0.0684 & 0.1158 & -0.1371 & 0.0946 \\
\hline & T-Statistic & -0.9387 & -0.4014 & -1.2048 & 0.3280 & 0.2790 & 0.2832 & -0.7368 & 0.3659 \\
\hline & \% Change & $2.45 \%$ & $2.22 \%$ & $7.26 \%$ & $1.62 \%$ & $-0.58 \%$ & $-2.11 \%$ & $2.77 \%$ & $-1.24 \%$ \\
\hline
\end{tabular}

Note: The Percent Change row represents the average percent change over the sample of patients in the probability of receiving a generic prescription when the patient's insurance status changes from Selfpay to the appropriate insurance category. 
Table 5a. Estimated Coefficients on Demographic Variables, Geographic Variables, and Average Characteristics for Non-Medicare Sample

\begin{tabular}{||l|cc|ccc||}
\hline Variable & $\begin{array}{c}\text { Simple } \\
\text { Probit } \\
\text { Coefficient }\end{array}$ & $\begin{array}{c}\text { Simple } \\
\text { Probit T- } \\
\text { statistic }\end{array}$ & $\begin{array}{c}\text { Random } \\
\text { Effects Probit } \\
\text { Coefficient }\end{array}$ & $\begin{array}{c}\text { Random } \\
\text { Effects Probit } \\
\text { T-statistic }\end{array}$ & $\begin{array}{c}\text { \% Change } \\
\text { in Generic }\end{array}$ \\
\hline Constant & -1.0478 & -6.5433 & -0.8082 & -4.2186 & \\
Female & -0.0066 & -5.0320 & -0.0055 & -4.7533 & $-0.17 \%$ \\
Non-White & -0.0393 & -1.0391 & -0.0422 & -1.2452 & $-1.35 \%$ \\
Hispanic & 0.1536 & 2.1158 & 0.1282 & 2.0013 & $4.12 \%$ \\
Specialist & -0.0089 & -0.0963 & -0.0212 & -0.2335 & $-0.67 \%$ \\
Mandatory Substitution & 0.0298 & 0.7031 & 0.0172 & 0.2686 & $0.54 \%$ \\
Twoline Prescription & -0.0683 & -1.1782 & -0.1155 & -1.3307 & $-3.58 \%$ \\
Mean Age & -0.0577 & -1.3506 & -0.0455 & -0.7123 & $-1.43 \%$ \\
Percent Female & 0.0043 & 2.3187 & 0.0042 & 1.6467 & $0.13 \%$ \\
Percent Black & 0.0620 & 0.5341 & -0.1705 & -1.0939 & $-5.37 \%$ \\
Percent Hispanic & 0.0884 & 0.7378 & 0.1376 & 0.8116 & $4.34 \%$ \\
Percent Medicaid & -0.0236 & -0.1655 & -0.0730 & -0.3315 & $-2.30 \%$ \\
Percent Private & 0.0950 & 0.5904 & 0.1789 & 0.7636 & $5.63 \%$ \\
Percent HMO/Pre-Paid & -0.0193 & -0.2225 & 0.0817 & 0.7113 & $2.57 \%$ \\
Midwest & 0.2206 & 2.0505 & 0.2312 & 1.5982 & $7.28 \%$ \\
South & -0.127 & -1.8711 & -0.1944 & -1.7359 & $6.34 \%$ \\
West & -0.2738 & -4.2282 & -0.3280 & -3.2570 & $-10.40 \%$ \\
\hline$\rho$ & 0.0164 & 0.2377 & -0.0237 & -0.2131 & $-0.80 \%$ \\
\hline \hline
\end{tabular}

Note: The dependent variable is 1 if the generic is prescribed, 0 otherwise. The sample size is 6251 . The Mean and Percent Variables refer to the mean and percent charateristics of the physician whom the patient visits. The omitted region category is Northeast. The omitted insurance categories are Selfpay and Percent Selfpay. The percent changes in generic prescription are calculated as the average over the sample of the percent change in the probability of receiving a generic. For example, the percent change in the probability of generic prescription for age is the average percentage change for a one year increase in age. For the dummy variables, the percent change in generic prescription represents the average percentage change that occurs when a person moves into the category represented by the dummy variable. The parameter $\rho$ is the estimated variance of the random physician effect. 
Table 5b. Estimated Coefficients for Drug Class Dummy Variable for Non-Medicare sample

\begin{tabular}{|c|c|c|c|c|c|}
\hline Drug Class & $\begin{array}{c}\text { Simple } \\
\text { Probit } \\
\text { Coefficient }\end{array}$ & $\begin{array}{c}\text { Simple } \\
\text { Probit T- } \\
\text { Statistic }\end{array}$ & $\begin{array}{c}\text { Random } \\
\text { Effects } \\
\text { Probit } \\
\text { Coefficient }\end{array}$ & $\begin{array}{c}\text { Random } \\
\text { Effects T- } \\
\text { Statistic }\end{array}$ & $\begin{array}{c}\% \\
\text { Change } \\
\text { in } \\
\text { Generic }\end{array}$ \\
\hline Antimicrobials & 0.9707 & 7.3238 & 0.8475 & 7.5079 & $25.97 \%$ \\
\hline Cardiovascular/Renals & 0.5281 & 3.0690 & 0.4295 & 2.9246 & $11.44 \%$ \\
\hline Central Nervous System & 0.7893 & 5.0378 & 0.4936 & 3.8508 & $13.48 \%$ \\
\hline $\begin{array}{l}\text { Hormones/Hormone } \\
\text { Mechanisms }\end{array}$ & 0.9621 & 6.3904 & 0.8543 & 7.1325 & $26.23 \%$ \\
\hline Skin/Mucous Membrane & -0.6930 & -3.1159 & -0.7597 & -4.0647 & $-10.69 \%$ \\
\hline Ophthalmics & -0.1979 & -0.8026 & -0.1939 & -0.7644 & $-3.81 \%$ \\
\hline Respiratory Tract & -0.4278 & -1.9091 & -0.4254 & -2.4963 & $-7.32 \%$ \\
\hline
\end{tabular}

Note: The Omitted Drug Category is Pain Relief. 
Table 5c: Tests of Moral Hazard for the Non-Medicare Sample Equality of Individual Insurance Variables With Self-Payment

Random Effects Probit Results

\begin{tabular}{|c|c|c|c|c|c|c|c|c|c|}
\hline $\begin{array}{l}\text { Insurance } \\
\text { Variable }\end{array}$ & & $\begin{array}{c}\text { Anti- } \\
\text { Microbials }\end{array}$ & $\begin{array}{c}\text { Cardio- } \\
\text { vasuculars }\end{array}$ & Metabolics & Hormones & $\begin{array}{l}\text { Skin/Mucous } \\
\text { Membranes }\end{array}$ & Opthalmics & $\begin{array}{l}\text { Pain } \\
\text { Relief }\end{array}$ & $\begin{array}{c}\text { Respiratory } \\
\text { Tract }\end{array}$ \\
\hline \multirow[t]{3}{*}{ Medicaid } & Coefficient & -0.0587 & 0.2772 & -0.0531 & 0.3227 & 1.2206 & -0.2681 & -0.8476 & -0.2829 \\
\hline & T-Statistic & -0.7079 & 1.1397 & -0.2748 & 1.3657 & 5.6350 & -0.4498 & -1.8590 & -1.0616 \\
\hline & $\%$ Change & $2.23 \%$ & $-9.62 \%$ & $1.75 \%$ & $-12.56 \%$ & $-24.05 \%$ & $4.15 \%$ & $11.81 \%$ & $3.10 \%$ \\
\hline \multirow[t]{3}{*}{ Private } & Coefficient & -0.0627 & -0.2614 & -0.0594 & -0.2555 & 0.3225 & 0.1865 & 0.0877 & -0.3284 \\
\hline & T-Statistic & -1.0028 & -1.8622 & -0.5164 & -2.2088 & 1.4974 & 0.6112 & 0.6298 & -0.9172 \\
\hline & $\%$ Change & $2.38 \%$ & $7.72 \%$ & $1.96 \%$ & $9.45 \%$ & $-3.37 \%$ & $-3.81 \%$ & $-2.08 \%$ & $3.48 \%$ \\
\hline \multirow[t]{3}{*}{ HMO/Pre-Paid } & Coefficient & -0.0720 & -0.1690 & -0.2581 & -0.0395 & 0.1711 & -0.36666 & -0.0924 & 0.1194 \\
\hline & T-Statistic & -1.0510 & -0.8549 & -1.1865 & -0.2692 & 0.6798 & -0.7122 & -0.4459 & 0.4654 \\
\hline & $\%$ Change & $2.73 \%$ & $5.16 \%$ & $7.98 \%$ & $1.51 \%$ & $-1.57 \%$ & $5.32 \%$ & $2.00 \%$ & $-1.85 \%$ \\
\hline
\end{tabular}

Note: The Percent Change row represents the average percent change over the sample of patients in the probability of receiving a generic prescription when the patient's insurance status changes from Selfpay to the appropriate insurance category. 
Table 6a. Estimated Coefficients on Demographic Variables, Geographic Variables, and Average

Characteristics for Subsample From States with Permissive Substitution and One-Line Prescription Pads

\begin{tabular}{|c|c|c|c|c|c|}
\hline Variable & $\begin{array}{c}\text { Simple } \\
\text { Probit } \\
\text { Coefficient }\end{array}$ & $\begin{array}{c}\text { Simple } \\
\text { Probit T- } \\
\text { statistic }\end{array}$ & $\begin{array}{c}\text { Random } \\
\text { Effects } \\
\text { Probit } \\
\text { Coefficient }\end{array}$ & $\begin{array}{c}\text { Random } \\
\text { Effects } \\
\text { Probit T- } \\
\text { statistic }\end{array}$ & $\begin{array}{l}\text { \% Change } \\
\text { in Generic }\end{array}$ \\
\hline Constant & -0.7116 & -3.2876 & -0.3058 & -2.1314 & \\
\hline Age & -0.0049 & -3.5580 & -0.0046 & -3.5982 & $-0.15 \%$ \\
\hline Female & -0.0996 & -2.1944 & -0.0987 & -2.3144 & $-3.08 \%$ \\
\hline Non-White & 0.1071 & 1.1966 & 0.0729 & 0.7677 & $2.29 \%$ \\
\hline Hispanic & -0.0661 & -0.5446 & -0.0216 & -0.1694 & $-0.67 \%$ \\
\hline Specialist & -0.0309 & -0.6097 & 0.0015 & 0.0191 & $0.05 \%$ \\
\hline Mean Age & 0.0031 & 1.4438 & 0.0026 & 0.8684 & $0.08 \%$ \\
\hline Percent Female & -0.3024 & -2.0098 & -0.4116 & -2.0024 & $-12.77 \%$ \\
\hline Percent Black & -0.0829 & -0.5122 & -0.1294 & -0.5217 & $-4.02 \%$ \\
\hline Percent Hispanic & -0.2762 & -1.2782 & -0.6048 & -1.8494 & $-19.77 \%$ \\
\hline Percent Medicaid & -0.0741 & -0.3335 & 0.2124 & 0.7705 & $6.59 \%$ \\
\hline Percent Medicare & -0.2602 & -1.1909 & -0.1046 & -0.3110 & $-3.24 \%$ \\
\hline Percent Private & 0.0889 & 0.7378 & 0.0828 & 0.5005 & $2.60 \%$ \\
\hline Percent HMO/Pre-Paid & 0.1023 & 0.6858 & 0.1961 & 0.9247 & $6.09 \%$ \\
\hline Midwest & -0.3181 & -4.1594 & -0.2846 & -2.0753 & -9.00 \\
\hline South & -0.3782 & -1.6389 & -0.3035 & -2.0905 & -9.56 \\
\hline West & -0.1210 & -1.5274 & -0.0506 & -0.3592 & -1.66 \\
\hline$\rho$ & & & 0.2486 & 8.9792 & \\
\hline
\end{tabular}

Note: The dependent variable is 1 if the generic is prescribed, 0 otherwise. The sample size is 4334 . The Mean and Percent Variables refer to the mean and percent charateristics of the physician whom the patient visits. The omitted region category is Northeast. The omitted insurance categories are Selfpay and Percent Selfpay. The percent changes in generic prescription are calculated as the average over the sample of the percent change in the probability of receiving a generic. For example, the percent change in the probability of generic prescription for age is the average percentage change for a marginal increase in age. For the dummy variables, the percent change in generic prescription represents the average percentage change that occurs when a person moves into the category represented by the dummy variable. The parameter $\rho$ is the estimated variance of the random physician effect. 
Table 6b. Estimated Coefficients for Drug Class Dummy Variable for Subsample of States

\begin{tabular}{||l|cc|ccc||}
\hline Drug Class & $\begin{array}{c}\text { Simple } \\
\text { Probit } \\
\text { Coefficient }\end{array}$ & $\begin{array}{c}\text { Simple } \\
\text { Probit T- }\end{array}$ & $\begin{array}{c}\text { Random } \\
\text { Effects } \\
\text { Probit } \\
\text { Coefficient }\end{array}$ & $\begin{array}{c}\text { Random } \\
\text { Effects T- } \\
\text { Statistic }\end{array}$ & $\begin{array}{c}\% \\
\text { Change } \\
\text { in } \\
\text { Generic }\end{array}$ \\
\hline \hline Antimicrobials & 1.0911 & 6.0256 & 0.9663 & 5.5327 & $30.42 \%$ \\
Cardiovascular/Renals & 0.2749 & 1.1295 & 0.2083 & 0.8844 & $5.02 \%$ \\
Central Nervous System & 0.9789 & 4.4963 & 0.7562 & 3.8475 & $22.54 \%$ \\
$\begin{array}{l}\text { Hormones/Hormone } \\
\text { Mechanisms }\end{array}$ & 1.2321 & 6.0494 & 1.0499 & 5.7822 & $33.61 \%$ \\
Skin/Mucous Membrane & -0.7415 & -2.1264 & -0.7693 & -2.5869 & $-10.72 \%$ \\
Ophthalmics & -0.1861 & -0.5370 & -0.2589 & -0.7364 & $-4.89 \%$ \\
Respiratory Tract & -0.4596 & -1.2267 & -0.6572 & -0.8763 & $-9.80 \%$ \\
\hline \hline
\end{tabular}

Note: The Omitted Drug Category is Pain Relief. 
Table 6c: Tests of Moral Hazard for the Subsample of States

Equality of Individual Insurance Variables With Self-Payment

Random Effects Probit Results

\begin{tabular}{|c|c|c|c|c|c|c|c|c|c|}
\hline $\begin{array}{l}\text { Insurance } \\
\text { Variable }\end{array}$ & & $\begin{array}{c}\text { Anti- } \\
\text { Microbials }\end{array}$ & $\begin{array}{l}\text { Cardio- } \\
\text { vasuculars }\end{array}$ & Metabolics & Hormones & $\begin{array}{l}\text { Skin/Mucous } \\
\text { Membranes }\end{array}$ & Opthalmics & $\begin{array}{l}\text { Pain } \\
\text { Relief }\end{array}$ & $\begin{array}{c}\text { Respiratory } \\
\text { Tract }\end{array}$ \\
\hline \multirow[t]{3}{*}{ Medicaid } & Coefficient & -0.0601 & 0.5662 & -0.4754 & 0.3689 & 0.6119 & & -0.0442 & -0.1744 \\
\hline & T-Statistic & -0.4525 & 2.1803 & -1.6715 & 1.3718 & 1.4506 & & -0.1329 & -0.2107 \\
\hline & $\%$ Change & 2.31 & -17.97 & $15.37 \%$ & $-14.30 \%$ & $-7.11 \%$ & & $0.90 \%$ & $1.24 \%$ \\
\hline \multirow[t]{3}{*}{ Medicare } & Coefficient & -0.0158 & 0.3659 & -0.1588 & 0.3646 & 0.3173 & 0.5613 & 0.1288 & \\
\hline & T-Statistic & -0.0971 & 1.9667 & -0.7067 & 2.0125 & 0.7069 & 1.4929 & 0.4642 & \\
\hline & \% Change & $0.61 \%$ & $-10.91 \%$ & $5.60 \%$ & $-14.13 \%$ & $-2.87 \%$ & $-12.07 \%$ & $-2.89 \%$ & \\
\hline \multirow[t]{3}{*}{ Private } & Coefficient & -0.0131 & -0.0141 & -0.1429 & -0.1953 & 0.1343 & 0.1967 & 0.1173 & 0.1035 \\
\hline & T-Statistic & -0.1299 & -0.0733 & -0.9098 & -1.2772 & 0.4018 & 0.4451 & 0.5545 & 0.1259 \\
\hline & \% Change & $0.51 \%$ & $0.36 \%$ & $5.06 \%$ & $7.50 \%$ & $-1.03 \%$ & $-3.42 \%$ & $-2.62 \%$ & $-0.94 \%$ \\
\hline \multirow[t]{3}{*}{ HMO/Pre-Paid } & Coefficient & -0.0360 & 0.1690 & -0.1654 & -0.1174 & 0.4319 & 0.2841 & -0.0558 & -0.0515 \\
\hline & T-Statistic & -0.3196 & 0.5487 & -0.6498 & -0.5916 & 1.2590 & 0.5309 & -0.2142 & -0.0307 \\
\hline & $\%$ Change & $1.38 \%$ & $-4.68 \%$ & $5.83 \%$ & $4.54 \%$ & $-4.31 \%$ & $-5.21 \%$ & $1.13 \%$ & $0.41 \%$ \\
\hline
\end{tabular}

Note: The Percent Change row represents the average percent change over the sample of patients in the probability of receiving a generic prescription when the patient's insurance status changes from Selfpay to the appropriate insurance category. Sample sizes in empty cells are too small to estimate coefficients. 